\title{
Improving genomically recoded Escherichia coli for the production of proteins containing non-canonical amino acids
}

\author{
Jessica G. Perez ${ }^{1,2}$, Erik D. Carlson ${ }^{1,2}$, Oliver Weisser ${ }^{1,2}$, Camila Kofman $^{1,2}$, Kosuke Seki ${ }^{1,2}$, \\ Benjamin J. Des Soye ${ }^{1,2}$, Ashty S. Karim ${ }^{1,2}$, and Michael C. Jewett ${ }^{1,2,3,4^{*}}$
}

${ }^{1}$ Department of Chemical and Biological Engineering, Northwestern University, Evanston, IL 60208, USA

${ }^{2}$ Chemistry of Life Processes Institute, Northwestern University, Evanston, IL 60208, USA

${ }^{3}$ Center for Synthetic Biology, Northwestern University, Evanston, IL 60208, USA

${ }^{4}$ Simpson Querrey Institute, Northwestern University, Chicago, IL 60611, USA

*Corresponding author:
Prof. Michael C. Jewett
2145 Sheridan Road, Tech E-136
Evanston, IL 60208-3120
m-jewett@northwestern.edu
Tel: (+1) 8474675007 ; Fax (+1) 8474913728

Content Type: Article 


\section{Abstract}

A genomically recoded Escherichia coli strain that lacks all amber codons and release factor 1 $(C 321 . \Delta A)$ enables efficient genetic encoding of chemically diverse, non-canonical amino acids (ncAAs) into proteins. While C321. $\triangle A$ has opened new opportunities in chemical and synthetic biology, this strain has not been optimized for protein production, limiting its utility in widespread industrial and academic applications. To address this limitation, we describe the construction of a series of genomically recoded organisms that are optimized for cellular protein production. We demonstrate that the functional deactivation of nucleases (e.g., rne, endA) and proteases (e.g., Ion) increases production of wild-type superfolder green fluorescent protein (sfGFP) and sfGFP containing two ncAAs up to $\sim 5$-fold. Additionally, we introduce a genomic IPTG-inducible T7 RNA polymerase (T7RNAP) cassette into these strains. Using an optimized platform, we demonstrated the ability to introduce 2 identical $\mathrm{N}_{6}$-(propargyloxycarbonyl)-L-Lysine residues site specifically into sfGFP with a 17-fold improvement in production relative to the parent. We envision that our library of organisms will provide the community with multiple options for increased expression of proteins with new and diverse chemistries.

Keywords: non-canonical amino acids, orthogonal translational system, protein production, genomically recoded organism, amber suppression

\footnotetext{
Abbreviations: T7 RNA polymerase (T7RNAP), N6-(propargyloxycarbonyl)-L-Lysine (ProCarb), orthogonal translation system (OTS), orthogonal aminoacyl-tRNA synthetase (o-aaRS), orthogonal tRNA (o-tRNA), release factor-1 (RF-1), isopropyl $\beta$ - $\mathrm{D}-1$-thiogalactopyranoside (IPTG), p-azidophenylalanine (pAzF), multiplex automated genome engineering (MAGE), elastic-like polymer (ELP), pyrrolysine (Pyl), Methanosarcina mazei (M. mazei), and pyrrolysine synthetase (PyIRS).
} 


\section{Introduction}

The genetic code is a universal cipher that describes how mRNA codons are translated into proteins. Of the 64 available codons, 61 encode the twenty standard amino acids with the remaining three (UAA, UAG, UGA) responsible for signaling termination of protein synthesis. ${ }^{[1]}$ This biochemical principle extends through all kingdoms of life and for a long time was considered immutable. However, by the late 1970s variations in the genetic code, such as the reassignment of these codons to other amino acids, had been discovered. ${ }^{[2]}$ Today over twenty variations to the standard genetic code ${ }^{[3]}$ have spurred interest in utilizing these variations to encode non-canonical amino acids (ncAAs). Expanding the set of amino acids available for co-translational incorporation by the ribosome opens opportunities to site-specifically introduce new chemistries into proteins and has the potential to transform how we synthesize materials, study protein structure, and understand the translation system. ${ }^{[4-8]}$ For instance, synthesis of high molecular weight, high yielding polypeptides can be achieved inside cells ${ }^{[9]}$ while it can be difficult using other methods. ${ }^{[10]}$

The site-specific incorporation of ncAAs into proteins has been utilized for biophysical studies, ${ }^{[11,12]}$ creating new biocatalysts, ${ }^{[13]}$ synthesizing proteins containing post-translational modifications, ${ }^{[14-16]}$ and understanding translational processes and its evolution over time. ${ }^{[17]}$ Currently over 200 ncAAs have been incorporated into proteins co-translationally. ${ }^{[18,19]}$ These ncAAs include non-canonical a-amino acids (e.g., p-azidophenylalanine, fluorescent amino acids), as well as cyclic and backbone-extended (e.g., $\left.\beta-, \gamma^{-}, \delta_{-}\right)$monomers, among others. ${ }^{[20-30]}$ This is most often achieved in cells by amber suppression whereby the amber stop codon (UAG) is hijacked and used to encode a ncAA through the activity of a ncAA-specific orthogonal translation system (OTS). ${ }^{[31]}$ In general, OTSs are composed of two key components: (i) a suppressor tRNA that has been modified to decode the amber codon (o-tRNA) and (ii) an aminoacyl-tRNA synthetase that has been engineered to specifically recognize an ncAA of interest and aminoacylate it to the o-tRNA (o-aaRS). ${ }^{[32]}$ These components are orthogonal in that they interact principally with an ncAA of interest and have little crosstalk with the native translation 
components. In practice, these orthogonal components are expressed from a plasmid such as pEVOL, ${ }^{[33]}$ which encodes an o-tRNA as well as two copies of the associated o-aaRS. In the presence of their cognate ncAA, these orthogonal components facilitate the repurposing of amber codons as open channels encoding the ncAA.

Historically, a key limitation to OTSs for ncAA incorporation has been premature truncation of the recombinant protein at the UAG codon due to the activity of endogenous release factor-1 (RF-1). During translation, RF-1 recognizes and binds at amber codons, subsequently activating hydrolysis of peptidyl-tRNA to release the peptide chain. ${ }^{[34]}$ Thus, when attempting amber suppression the inherent competition between RF-1 and ncAA-o-tRNAs at amber codons causes inefficient incorporation of ncAAs and premature truncation, reducing the modified protein yield. Within the last decade, this interference was addressed with the completion of an Escherichia coli strain lacking all 321 UAG amber stop codons and RF-1, termed C321. $\triangle A$. The amber codon is completely orthogonal in this strain and is freed for total dedication to encoding an additional ncAA. ${ }^{[35]}$ Other approaches and strains have also been reported. ${ }^{[36,37]} C 321 . \Delta A$ has an increased ability to incorporate multiple ncAAs as compared to other $E$. coli strains, enabling many applications $^{[15,38-40]}$ most notably in biocontainment ${ }^{[40]}$. However, compared to standard commercially available protein production strains, like BL21(DE3), C321. $\Delta A$ is directly derived from the K-strain MG1655 (considered wild-type E. coli) and has not yet to our knowledge undergone strain development for improved protein production.

In this study, we sought to improve the utility of $C 321 . \Delta A$ by introducing genomic mutations and a robust, inducible expression system to enhance the strain's protein production utility. Given previous successes in improving protein production in E. coli systems by removing negative effectors, ${ }^{[41-43]}$ we targeted DNAase end $A,{ }^{[38,44]}$ RNAases $r n e^{[45]}$ and $r n b,{ }^{[46,47]}$ and proteases $/ o n^{[48]}$ and $\operatorname{omp}^{[48]}$ for functional inactivation in $C 321 . \Delta A$. We show that deletion of nuclease and protease genes in the strain increases production of superfolder green fluorescent protein (sfGFP) containing 2 UAGs by 2.3- and 5.6-fold with p-azidophenylalanine (pAzF) ("click" chemistry; 
photoreactive crosslinker) and $\mathrm{N}_{6}$-(propargyloxycarbonyl)-L-Lysine (ProCarb) (pyrrolysine analog), respectively. Next, we introduced the T7 promoter system ${ }^{[49,50]}$ into $C 321 . \Delta A$, given the advantages of high recombinant protein expression using this system. We present the construction of several strains featuring an isopropyl $\beta$-D-1-thiogalactopyranoside (IPTG) inducible T7RNAP cassette and demonstrate up to a 17-fold improvement in production of sfGFP containing 2 ProCarb residues using these strains. We envision that the library of organisms described here will be an important resource and provide the community with multiple strain options for expression of proteins containing ncAAs with increased protein yield.

\section{Results and Discussion}

Functional deactivation of proteases and nucleases enhances sfGFP production in C321. $\triangle A$

We hypothesized that reducing the activity of negative effectors of protein synthesis (e.g., proteases and nucleases) would stabilize critical synthetic intermediates and thus increase protein production in $C 321 . \Delta A$. To test this hypothesis, we prepared $C 321 . \Delta A$ derivatives featuring combinatorial functional inactivations of two proteases, two RNAses, and one DNAse using multiplex automated genome engineering (MAGE) $)^{[51]}$ (Figure 1A; Table 1). The Lon protease was deactivated using a mutagenic MAGE oligonucleotide to remove its promoter. This mutation is similar to the Lon protease mutation found in $B L 21(D E 3)$ where a transposable element, IS186, inserted directly into the Ion promoter preventing Lon's expression. ${ }^{[52]}$ The point mutation D103A was introduced into ompT to eliminate proteolytic activity while maintaining its structural motifs in order to preserve OmpT's possible chaperone function. ${ }^{[53,54]}$ RNAse $E$, encoded by rne, was truncated by inserting a stop codon at nucleotide 131 (rne131), a mutation which was previously found to increase mRNA half-life. ${ }^{[45,55]}$ RNAse II (encoded by $r n b$ and involved with mRNA degradation ${ }^{[56]}$ ) and Endonuclease I (encoded by endA and capable of generating breaks in double-stranded $D N A^{[57]}$ ) were similarly truncated by inserting a stop codon followed by a 
frameshift mutation in the first quarter of their open reading frames. ${ }^{[51]}$ Starting with the parental strain C321. $\triangle A$, these mutations were made in single, double, and some triple and quadruple combinations. Mutations were screened by multiplex allele-specific colony (MASC) $\mathrm{PCR}^{[58]}$ or colony PCR and confirmed by DNA sequencing. The average doubling times for the MAGEmodified strains were measured in 2 XYT media and were determined to be within $12 \%$ of the parental strain (Figure 1B), suggesting that the gene disruptions did not drastically affect cellular fitness.

A

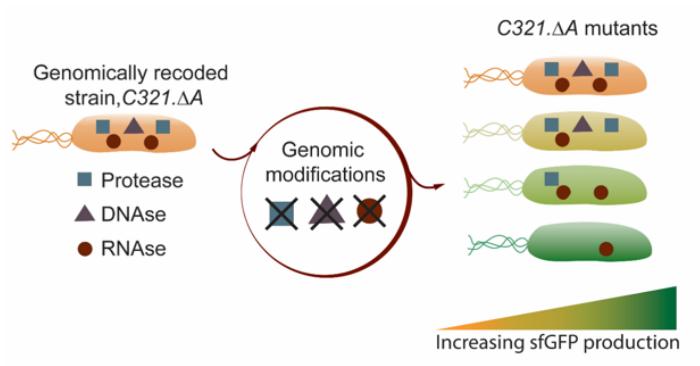

C

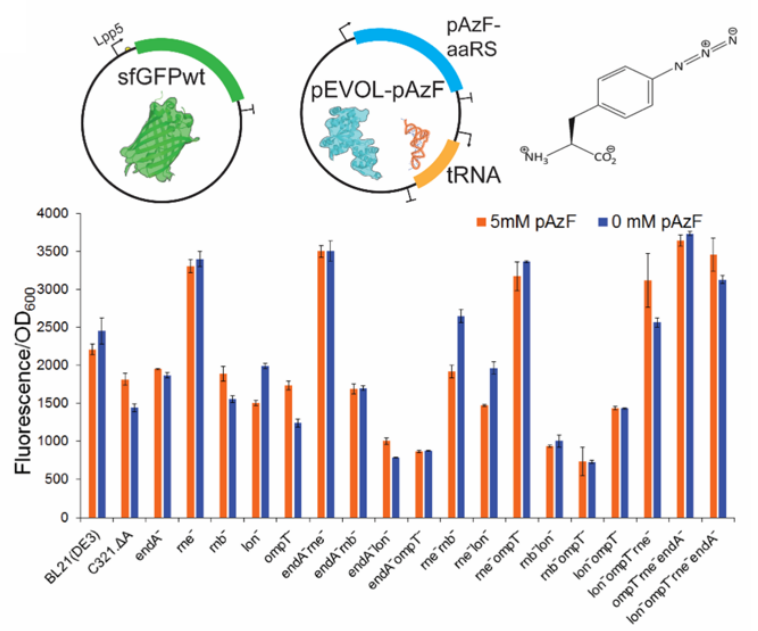

B

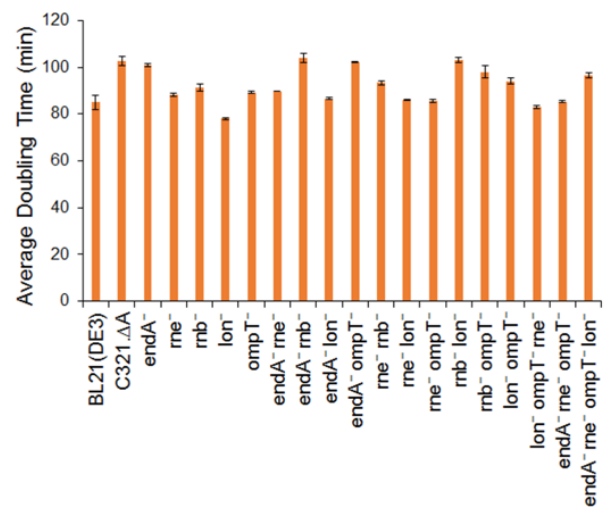

D
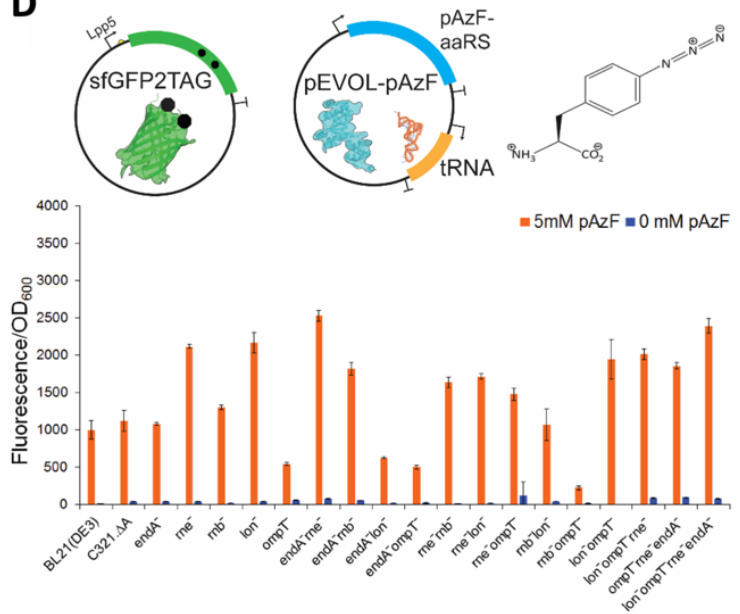

Figure 1. Functional inactivation of nucleases and proteases creates robust, high protein production strains for ncAA incorporation. (A) Mutagenic oligonucleotides were introduced into C321. $\triangle A$, targeting two proteases (Ion and ompT), two RNAases ( $r n e$ and $r n b$ ), and a DNAase (endA) for functional inactivation. Through multiple rounds of multiplex automated genome engineering (MAGE) several C321. $\triangle A$ mutants were generated. (B) C321. $\triangle A$ mutant strains were grown at $32{ }^{\circ} \mathrm{C}$ in 2 XYT media in a sterile 96 -well polystyrene plates. Optical density at $600 \mathrm{~nm}$ was measured every $10 \mathrm{~min}$ for $12 \mathrm{~h}$. Error bars represent biological duplicates and technical triplicates. (C) The protein production capability of the modified C321. $A A$ strains were analyzed by expressing wild-type sfGFP (sfGFP-wt), regulated by a strong endogenous promoter pLpp5, and the pAzF orthogonal translation system expressed on $\mathrm{pEVOL-pAzF}$. For all conditions $1 \mathrm{mM}$ 
IPTG, $0.02 \%$ arabinose and $5 \mathrm{mM}$ pAzF (orange bars) or 0mM pAzF (blue bars) were added at $\mathrm{OD}_{600}$ 0.6-0.8. (D) Modified C321. $\triangle A$ strains were analyzed for the ability to suppress two amber codons in sfGFP at positions 190 and 212 in the presence (orange) or absence (blue) of $5 \mathrm{mM}$ pAzF. For (C) and (D) error bars represent one standard deviation for biological triplicates and technical triplicates.

Table 1: Proteases and Nucleases Targeted in this study.

\begin{tabular}{|c|c|c|c|c|c|}
\hline $\begin{array}{l}\text { General } \\
\text { Function }\end{array}$ & $\begin{array}{c}\text { Gen } \\
\text { e }\end{array}$ & Specific Function & Mutation & Phenotype & Ref. \\
\hline DNA Stability & $\begin{array}{l}\text { end } \\
A\end{array}$ & Endonuclease I & $\begin{array}{l}\text { GGATGT } 748 \\
\text { TAACTGA }\end{array}$ & $\begin{array}{l}\text { Truncated at } 748 \\
\text { nt }\end{array}$ & [44] \\
\hline \multirow[t]{2}{*}{ RNA Stability } & rne & RNase B & $\begin{array}{l}\text { GGT } 584 \\
\text { TAACTGA }\end{array}$ & $\begin{array}{l}\text { Truncated at } 584 \\
\text { nt }\end{array}$ & [45] \\
\hline & $r n b$ & RNAase $\mathrm{E}$ & $\begin{array}{l}\text { GACGCC } 632 \\
\text { TAACTGA }\end{array}$ & $\begin{array}{l}\text { Truncated at } 632 \\
\text { nt }\end{array}$ & [59] \\
\hline \multirow[t]{2}{*}{ Protein Stability } & Ion & $\begin{array}{l}\text { ATP-dependent } \\
\text { protease }\end{array}$ & $\begin{array}{l}\text { Removal of } \\
\text { promoter }\end{array}$ & Unknown & [60] \\
\hline & $\begin{array}{l}\text { omp } \\
T\end{array}$ & $\begin{array}{l}\text { Outer membrane } \\
\text { protease VII }\end{array}$ & D103A & $\begin{array}{l}\text { Elimination of } \\
\text { proteolytic activity }\end{array}$ & {$[53,54]$} \\
\hline
\end{tabular}

To assess the protein production capacity of $C 321 . \Delta A$ and its mutants, we transformed all strains with the pLpp5-sfGFP-wt plasmid, which expresses wild-type sfGFP protein (sfGFP-wt) off a strong IPTG-inducible endogenous promoter, Lpp $5^{[61]}$ along with a pEVOL plasmid encoding the orthogonal translation system (OTS) for $p$-azidophenylalanine (pAzF) ${ }^{[33]}$ (Figure 1C). The strains were grown. IPTG was added to induce sfGFP-wt expression, and sfGFP was quantified as a measure of fluorescence/O.D.600. The $r^{-}$mutant had the strongest impact on sfGFP-wt expression, implying that mRNA stability may be the largest limitation for expression of sfGFP-wt in C321. $\triangle A$. Interestingly, the mutation combination most similar to $B L 21(D E 3)$, Ion ${ }^{-}$omp $T^{-}$, expressed sfGFP-wt at levels $44 \%$ less than BL21(DE3). This observation was not explored further, but it most likely stems from the inherent differences between B- and K-strains. Furthermore, we observed that the addition of $e n d A^{-}$to strains containing $\mathrm{rne}^{-}$added a minor boost in sfGFP-wt expression. Ultimately, the top mutants for expression of sfGFP-wt were rne - 
end $A^{-}$rne ${ }^{-}$, and omp $T^{-}{ }^{-}$ne ${ }^{-} e n d A^{-}$, with the top mutant outproducing both $B L 21(D E 3)$ and the parental strain by 2.6 -fold.

We next explored whether the C321. $\Delta A$ mutant strains could better incorporate ncAAs during protein expression by using an sfGFP-expressing construct containing two amber stop codons (sfGFP-2UAG) (Figure 1D). In this case, full length sfGFP expression and fluorescence is dependent on the successful incorporation of pAzF at each amber codon. In the absence of pAzF, any fluorescence measured results from non-specific incorporation at amber codons. Under these conditions, BL21(DE3)'s ability to express sfGFP-2UAG is reduced compared to C321. $\triangle A$ likely a result of RF-1 being active in BL21(DE3). As was the case with sfGFP-wt, the $r n e^{-}$strain and several mutations combined with $r n e^{-}$demonstrated increased productivity. The top-performing mutant was $r n e^{-} e n d A^{-}$with a 2.3-fold improvement as compared to the parental strain. Comparable in performance, lon ${ }^{-} \mathrm{omp} T^{-}{ }^{-} r n e^{-} e n d A^{-}$was the next top-performing mutant. Absolute protein expression was quantified by purifying sfGFP using a Strep-tag-Strep-Tactin column after a 20-h expression assay in $1 \mathrm{~L}$ 2xYT media (Table S1).

In order to test the limits of these systems, top-performing mutants for both sfGFP-wt- and sfGFP-2UAG-expression were tested for the ability to incorporate pAzF at 10 amber codons. We co-transformed top C321. $\mathrm{A}$ mutants with a plasmid expressing an elastic-like polymer (ELP) containing 10UAGs fused to sfGFP-wt at the C-terminus and the pEVOL-pAzF plasmid, preventing potential loss in fluorescence due to multiple-site ncAA incorporation into sfGFP (Figure 2A). In this case, all 10UAGs in the ELP must be suppressed in order for the sfGFP-wt moiety to be expressed and produce fluorescence. The advantage of the genomically recoded strain over BL21(DE3), which contains RF-1, to incorporate multiple ncAAs was especially pronounced here. None of the mutants in this case displayed a significant improvement compared to $C 321 . \triangle A$; however, the system showed a 12-fold improvement over $B L 21$ (DE3). This suggests 
that the ability of the OTS components to incorporate ncAAs, rather than the strain's protein production capability, is the limiting factor under these conditions.

\section{A}
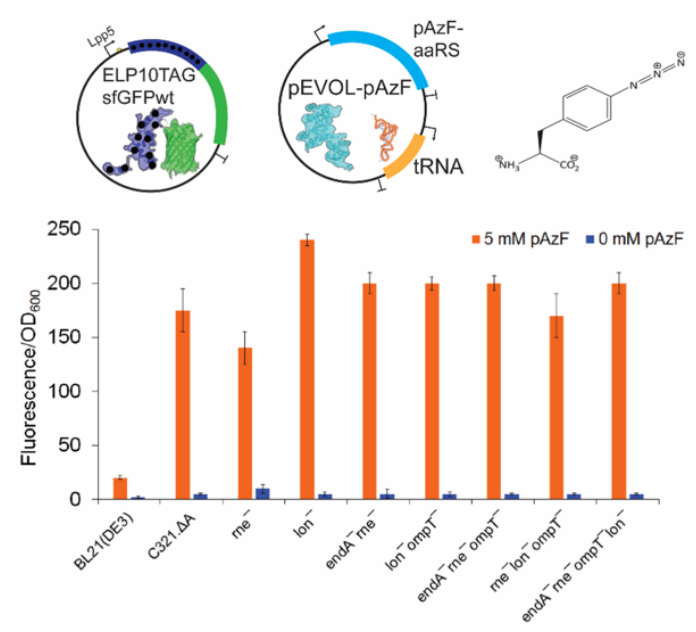

B

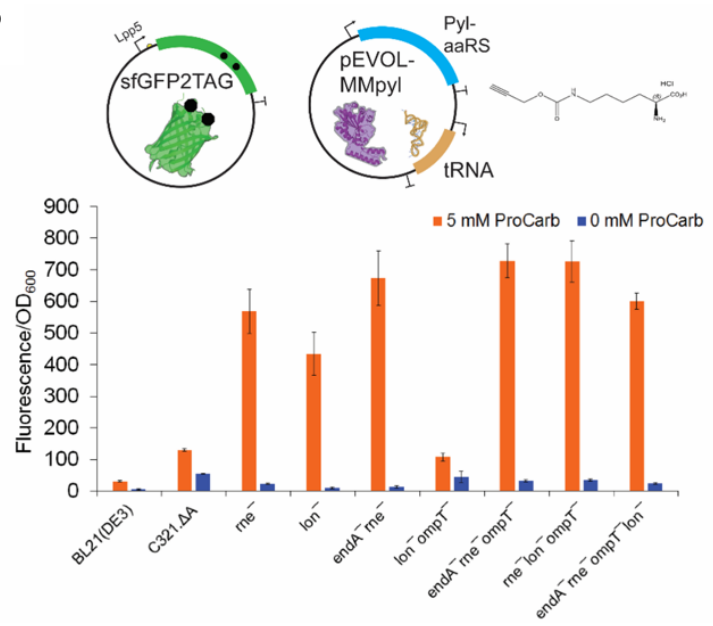

Figure 2. Reducing protease and nuclease activity improves multiple-site ncAA incorporation across orthogonal translation systems. (A) Elastin-like polypeptide (ELP) containing 10 amber codons and fused to sfGFP-wt at its $C$-terminus was expressed with pEVOLpAzF in top C321. $\triangle A$ mutants. For all conditions $1 \mathrm{mM} \mathrm{IPTG,} 0.02 \%$ arabinose and $5 \mathrm{mM}$ pAzF (orange bars) or OmM pAzF (blue bars) were added at $\mathrm{OD}_{600}$ 0.6-0.8. (B) Expression of sfGFP containing two amber codons for incorporation of the pyrrolysine analog, $\mathrm{N}_{6-}$ (propargyloxycarbonyl)-L-Lysine (ProCarb) using the orthogonal translational system for pyrrolysine was tested in top C321. $\triangle A$ mutants. For all panels error bars represent one standard deviation for biological triplicates and technical triplicates.

We next tested conditions where mRNA and protein stability may be a limitation by expressing sfGFP2UAG in the presence of a pEVOL plasmid encoding the pyrrolysine (Pyl) OTS system from Methanosarcina mazei (pEVOL-MMpyl) ${ }^{[62]}$ (Figure 2B). This OTS was chosen because the Pyl synthetase (PyIRS) is known to be very difficult to express recombinantly. ${ }^{[63,64]}$ Because there is no commercial source of Pyl and the ncAA is tedious and expensive to synthesize ${ }^{[65]}$ we used the pyrrolysine derivative $\mathrm{N}_{6}$-(propargyloxycarbonyl)-L-Lysine (ProCarb) in these experiments. We observed that the C321. $\Delta A$ mutants had a drastic improvement over C321. $\triangle A$ and BL21(DE3) for expression of sfGFP containing two ProCarbs. The top mutant, end ' $^{\text {rne }}{ }^{-} \mathrm{omp} T^{-}$, showed a 5.6-fold improvement compared to the parental strain. These results 
demonstrate the advantage of reducing protease and nuclease activity when using o-aaRSs with known solubility issues such as PyIRS. ${ }^{[63,64]}$

Genomic introduction of a T7 RNA polymerase cassette increases utility of C321. $\triangle A$

After improving protein production capabilities in C321. $\triangle A$ we wanted to further enhance its utility by providing transcriptional tuning capabilities. Transcriptional tuning is a powerful tool for efficient recombinant protein production in E. coli. Many challenges such as product toxicity, formation of inclusion bodies, and metabolic burden are associated with non-optimal (too high or too low) levels of recombinant protein expression. Tunable expression systems allow for the adjustment of recombinant protein expression using a small molecule inducer to maximally exploit the cell's metabolic capability. Thus, the ability to tune recombinant protein expression is a staple for many protein expression projects. Within this realm, use of the T7 RNA polymerase (T7RNAP) within $B L 21(D E 3)$ is the most popular approach for producing proteins due to the enzyme's high activity, tunability, and orthogonality. To use this system, a gene of interest is cloned behind a T7 promoter and recognized exclusively by the phage T7RNAP encoded on the genomic DE3 cassette and induced by the addition of IPTG. ${ }^{[48]}$ This allows for highly productive and orthogonal recombinant protein expression that is tunable by controlled addition of IPTG. To leverage the power of the T7RNAP in C321. $\triangle A$, a synthetic T7RNAP cassette was synthesized by amplifying T7RNAP from the BL21(DE3) genome and adding an upstream terminator (to transcriptionally isolate the cassette), a CmR gene as a selectable marker, and $45 \mathrm{bp}$ of genomic homology to the genomic insertion site on the 5' and 3' end to facilitate incorporation into the genome (Figure S1). Using $\lambda$-red mediated homologous recombination, ${ }^{[58,66]}$ the cassette was inserted into the top C321. $\triangle A$ mutant strains. Using MAGE, the $\mathrm{CmR}$ marker was removed, and finally the full cassette and insertion site were verified by sequencing to yield a series of C321. $\Delta A-T 7$ strains (Figure 3A). 


\section{A}

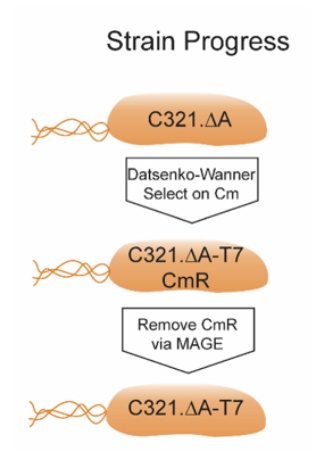

B

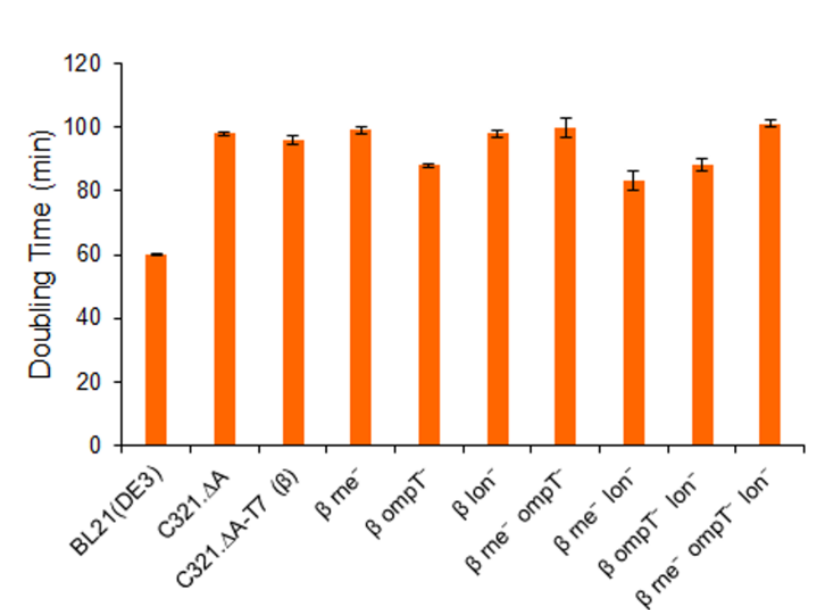

Genotype at site of insertion

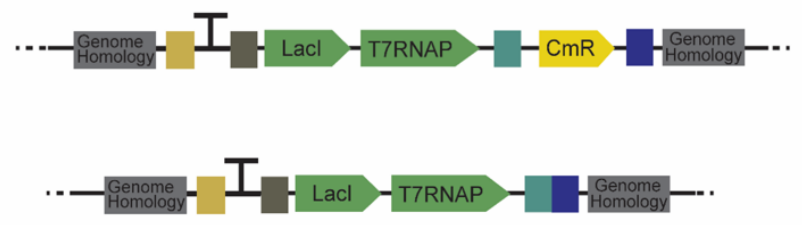

C
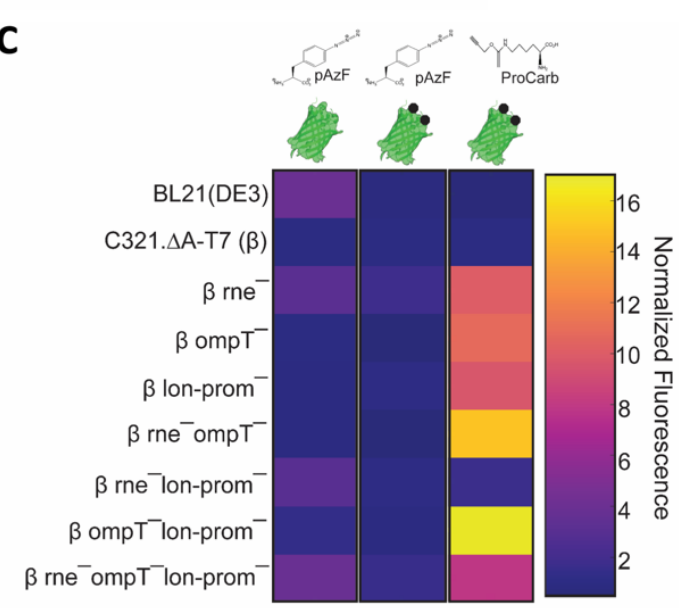

Figure 3: Genomic insertion of the T7RNAP cassette improves utility of $C 321 . \Delta A$ mutant strains. (A) The T7RNAP cassette was inserted into top C321. $\triangle A$ mutant strains using DatsenkoWanner. After recovery, transformed cells were plated on LB plates containing $34 \mu \mathrm{g} / \mathrm{mL}$ chloramphenicol, selecting for strains that incorporated the T7RNAP cassette. The selectable marker was then removed through several cycles of multiplex automated genome engineering (MAGE). The resultant strains were termed C321. $\triangle A-T 7$. (B) Strains were grown at $32^{\circ} \mathrm{C}$ in $2 x Y T$ media in a sterile 96 -well polystyrene plates. Optical density at $600 \mathrm{~nm}$ was measured every 10 min for $12 \mathrm{~h}$. Error bars represent biological duplicates and technical triplicates. (C) Heat map depicts the normalized fluorescence (Fluorescence/OD $\mathrm{D}_{600}$ ) for various reporter proteins relative to C321. $\triangle A-T 7(\beta)$ within each vertical condition. Column 1: pET28a-sfGFP-wt + pEVOLpAzF + 5 $\mathrm{mM}$ pAzF $+1 \mathrm{mM}$ IPTG $+0.02 \%$ Arabinose; Column 2: pET28a-sfGFP2UAG + pEVOLpAzF +5 $\mathrm{mM}$ pAzF + $1 \mathrm{mM}$ IPTG + 0.02\% Arabinose; Column 3: pET28a-sfGFP2UAG + pEVOL-MMpyl + $5 \mathrm{mM}$ ProCarb $+1 \mathrm{mM}$ IPTG $+0.02 \%$ Arabinose. Normalized Fluorescence data is shown in Figure S4 and S5.

To test functionality of the T7RNAP cassette, a reporter plasmid expressing sfGFP-wt or sfGFP-2UAG regulated by a T7 promoter was transformed into the $C 321 . \Delta A-T 7$ strains along with pEVOL-pAzF and the ability of the strains to express sfGFP using the T7RNAP was assessed. Here, all strains including BL21(DE3) expressed the reporter proteins at levels much lower than sfGFP-wt/2UAG expression regulated by Lpp5 (Figure S2). Because T7 systems often utilize 
pET plasmids, the reporter plasmids were switched to a pET28a backbone. ${ }^{[67]}$ With the new plasmids BL21(DE3)'s expression of sfGFP-wt (Figure S3A) increased to near the same levels as expression of pLpp5-sfGFPwt. However, expression of sfGFP-wt, directed by T7RNAP, remained low in the C321. $\triangle A$ mutants.

We hypothesized that T7RNAP-based expression in C321. $\triangle A$ could be improved by introducing genomic mutations similar to those present in BL21 (DE3) and its derivatives. To test this, we reconstructed the C321. $A A$ strains containing T7RNAP by addition of the T7RNAP cassette into $C 321 . \Delta A$ (to yield strain $\beta$ ), followed by the combinatorial introduction of inactivating mutations to $r n e, o m p T$, and lon. The doubling times of the resulting strains in 2xYT media at 32 ${ }^{\circ} \mathrm{C}$ were within $18 \%$ of the parental strain (Figure 3B). When assessing T7RNAP-driven expression using these strains, we observed an increase in productivity of 2.2-fold and 3.1-fold for sfGFP-wt/pAzF and sfGFP-2UAG/pAzF respectively (Figure S4).

In particular, $\beta$ rne ${ }^{-o m p} T$ - lon-; featuring the same combination of mutations as BL21 (DE3), showed an improvement in sfGFP-wt expression of 3.7-fold over the parental strain (Figure 3C). When expressing pET28a-sfGFP2UAG with pEVOL-pAzF, $\beta$ rne ${ }^{-}$showed a 1.9-fold improvement over $\beta$ and 2.3-fold improvement over BL21(DE3). It appears that no matter the RNA polymerase used for expression, $r n e^{-}$is the most beneficial mutation for expression of sfGFP in C321. $\triangle A$ strains. Lastly, when expressing sfGFP-2UAG with pEVOL-MMpyl, we observed a 17-fold improvement compared to $\beta$. In this case, we suspect the highest fold improvement was observed due to the poor solubility of PyIRS.

\section{Conclusions}

The recoded strain C321. $\triangle A$ has a fully orthogonal amber codon for site-specific ncAA incorporation. However, it has not previously been optimized for protein production in vivo. To address this gap, we applied $\mathrm{MAGE}^{[51]}$ to generate a series of $C 321 . \Delta A$ derivatives with combinatorial knockouts of several nucleases and proteases. Protein yield from each strain was 
quantified as a function of sfGFP fluorescence/O.D.600 in order to assess the impacts of these knockouts on protein production. This analysis revealed that the functional inactivation of three targets (omp $T^{-} r n e^{-} e n d A$ ) improved sfGFPwt production by $\sim 2.6$-fold, while inactivation of rne and endA improved the production of sfGFP featuring two pAzF residues (sfGFP2pAzF) by 2.3fold. Pushing the limits of the system, inactivation of the Lon protease dramatically improved expression of elastin-like polymer featuring 10 pAzF residues. Finally, use of the pyrrolysyl-tRNA synthetase improved $\sim 5.6$-fold in a top mutant as compared to the parental strain, suggesting applicability of our approach to cases in which mRNA and/or protein stability are known issues. ${ }^{[63,64]}$ Notably, across all trials and experiments the functional inactivation of the RNAse rne was the most impactful.

To introduce precise control of target protein expression via transcriptional tuning, we applied $\lambda$-Red-mediated homologous incorporation to introduce a synthetic cassette encoding an IPTG-inducible T7 RNA polymerase into our strains. When this cassette was inserted into C321. $\triangle A$ prior to the combinatorial inactivation of ompT, rne, and lon, improvements of up to 3.7and 1.9-fold were observed for sfGFPwt and sfGFP2pAzF, respectively, as compared to the parental strain. Incorporation of pyrrolysine also improved significantly in these strains, again likely as a result of improved PyIRS solubility. Importantly, the top-performing T7 strains developed in this study all significantly outperformed BL21 (DE3) in terms of both yield and ability to incorporate ncAAs at amber codons.

Looking forward, as our ability to increase efficiencies of OTSs improve so will the need for optimized strains for the production of proteins containing ncAAs. For example, new efforts to engineer tethered ribosomes in cells offer exciting new dimensions for expanding the chemistry of life. ${ }^{[68-72]}$ For example, Orelle et al. first demonstrated the evolvability of tethered ribosomes by selecting otherwise dominantly lethal rRNA mutations in the peptidyl transferase center that facilitate the translation of problematic protein sequences. ${ }^{[71]}$ This, supported by increases in 
biomanufacturing should make possible new avenues in engineering molecular translation systems.

\section{Materials and Methods}

Reagents, Buffers and plasmids

Chemicals and media were purchased from Sigma Aldrich (St. Louise, MO, USA) unless otherwise designated. Phusion High-Fidelity DNA Polymerase, Taq DNA polymerase with Standard Taq Buffer, T4 DNA ligase, dNTP, Quick-load DNA Ladders, BL21(DE3) and restriction endonuclease were purchased from New England Biolabs (NEB, Ipswich, MA, USA). Multipex PCR Kits used for MASC PCR were purchased from QIAGEN (Hilden, NRW, DE). Plasmids were extracted using Omega E.Z.N.A DNA Isolation Kit (Omega Bio-Tek, Norcross, GA, USA). DNA was column purified or gel extracted using OMEGA HiBind DNA Mini Columns and OMEGA E.Z.N.A Gel Extraction Kit, respectively. Genomic DNA was isolated with Omega E.Z.N.A. Bacterial DNA Kit. All DNA oligonucleotides were purchased from Integrated DNA Technologies (IDT, Coralville, IA, USA). The ncAA pAzF was purchased from P212121, LLC (Ann Arbor, MI, USA) and ProCarb was purchased from BioFine, Inc (Vancouver, BC, CA). SYBR Safe, used in all agarose gels, and DH5 $\alpha$ were purchased from Thermo Fisher Scientific (Waltham, MA, USA). Synthetic E. coli C321. $\mathrm{A}$ (GenBank: CP06698.1) was received as a gift from Farren Isaacs. All oligonucleotides used for cloning are shown in Table S2. All vectors were cloned using Gibson Assembly. ${ }^{[73]} \mathrm{pLpp} 5$ plasmids were derived from pDTT1 vector. ${ }^{[74]} \mathrm{pET}$ vectors were derived from pET28a vectors.

\section{Construction of C321. $\triangle A$ mutants}

The strains in this study were generated from $C 321 . \Delta A^{[75]}$ by disrupting genes of interest using mutagenic oligonucleotides via MAGE ${ }^{[58]}$ (Table S2). Cultures were grown in LB-Lennox media (10 g/L Trypton, $5 \mathrm{~g} / \mathrm{L}$ Yeast Extract, and $5 \mathrm{~g} / \mathrm{L} \mathrm{NaCl}$ ) at $32^{\circ} \mathrm{C}$ and $250 \mathrm{rpm}$ throughout the 
MAGE cycle steps. ${ }^{[58]}$ Single, double, several triple and quadruple mutations were made to endA, rne, rnb, lon, and ompT, to investigate the effect of reduced nuclease and protease activity on expression of protein containing multiple ncAAs. Multiplex allele-specific colony (MASC) PCR was performed to screen for gene mutations by using wild-type forward (-wt-f) or mutant forward (mut-f) primers and reverse primers (-r; Table S2). Wild-type and mutant forward primers were identical except at the 3 '-ends of the oligonucleotide, and the reverse primers were used for detection of both wild-type and mutant alleles. The mutant allele was amplified using the mutant forward and reverse promoter set (-mut-f and $-r$ ) which resulted in a band on an electrophoresis gel but not with the wild-type forward and reverse primer set (-wt-f and $-r)$. MASC PCR was performed in $10 \mu \mathrm{L}$ reactions by using a Multiplex Master Mix at $95^{\circ} \mathrm{C}$ for $15 \mathrm{~min}$, with 30 cycles of $95^{\circ} \mathrm{C}$ for $30 \mathrm{~s}, 65^{\circ} \mathrm{C}$ for $30 \mathrm{~s}$, and $72^{\circ} \mathrm{C}$ for $1 \mathrm{~min}$, and a final extension of $72^{\circ} \mathrm{C}$ for $5 \mathrm{~min}$. Selection for lon mutants were performed separately in $10 \mu \mathrm{L}$ reactions using Taq DNA polymerase with Standard Taq Buffer at $95^{\circ} \mathrm{C}$ for $15 \mathrm{~min}$, with 20 cycles of $95^{\circ} \mathrm{C}$ for $30 \mathrm{~s}, 55^{\circ} \mathrm{C}$ for $30 \mathrm{~s}$, and $68^{\circ} \mathrm{C}$ for $2 \mathrm{~min}$, and a final extension of $68^{\circ} \mathrm{C}$ for $5 \mathrm{~min}$. Mutant alleles were screened by running PCR products on a $2 \%$ agarose gel and confirmed by DNA sequencing by using sequencing primers (Table S2).

\section{Growth Curves}

Overnight cultures of strains were grown in 2X YT (16 g/L Trypton, $10 \mathrm{~g} / \mathrm{L}$ Yeast Extract, and $5 \mathrm{~g} / \mathrm{L} \mathrm{NaCl}$ ) media at $32^{\circ} \mathrm{C}$ at $250 \mathrm{rpm}$ and were diluted 1:50 in $100 \mu \mathrm{L}$ of $2 \mathrm{X} \mathrm{YT}$ media. Diluted cultures $(100 \mu \mathrm{L})$ were added to 96 -well polystyrene plates (Costar 3370; Corning Incorporated, Corning, NY, USA). The $\mathrm{OD}_{600}$ was measured at $10 \mathrm{~min}$ intervals for $20 \mathrm{hr}$ at $32^{\circ} \mathrm{C}$ in orbital shaking mode on a SynergyH1 plate reader (Biotek, Winooski, VT, USA). Growth data for each strain was obtained from three replicate wells and three independent cultures. Doubling time was calculated during exponential growth phase. 


\section{Assaying expression of GFP}

Strains were freshly transformed with the plasmids of interest. A single colony was inoculated into $5 \mathrm{~mL}$ of $2 X$ YT media with $35 \mu \mathrm{g} / \mathrm{mL}$ Kanamycin and $25 \mu \mathrm{g} / \mathrm{mL}$ Chloramphenicol $\left(\mathrm{Kan}_{35} \mathrm{Cm}_{25}\right)$ grown overnight at $32^{\circ} \mathrm{C}, 250 \mathrm{rpm}$. Overnight cultures were diluted 1:50 into $5 \mathrm{~mL}$ of fresh $2 \mathrm{X}$ YT media $\mathrm{Kan}_{35} \mathrm{Cm}_{25}$ in triplicate and grown at $32^{\circ} \mathrm{C}$ at $250 \mathrm{rpm} . \mathrm{OD}_{600}$ was monitored on a Libra S4 spectrophotometer (Biochrom, Cambridge, UK) until $\mathrm{OD}_{600}$ 0.6-0.8 at which point cultures were induced. Inducers consisted of either $5 \mathrm{mM}$ ncAA, $1 \mathrm{mM}$ IPTG, and 0.02\% arabinose or $0 \mathrm{mM}$ ncAA, $1 \mathrm{mM}$ IPTG, and $0.02 \%$ arabinose. Cultures were allowed to express for 20-24 hrs after induction prior to harvest. To assay fluorescence, overnight cultures were diluted 10 -fold in $2 \mathrm{X}$ YT media $\mathrm{Kan}_{35} \mathrm{Cm}_{25}$. The $\mathrm{OD}_{600}$ of the 10 -fold dilution was measured on a NanoDrop 2000c (Thermo Scientific, Waltham, USA) and multiplied by ten. $100 \mu \mathrm{L}$ of the 10 -fold dilution was added to 96-well polystyrene plates (Costar 3603) in triplicate. Fluorescence of the plates were measured on a Synergy $\mathrm{H} 1$ plate reader with a gain of 60 . Normalized fluorescence was obtained by dividing fluorescence reading (normalized to $2 \mathrm{X}$ YT media $\mathrm{Kan}_{35} \mathrm{Cm}_{25}$ wells) by $\mathrm{OD}_{600}$ read on the NanoDrop 2000c.

\section{Construction of T7RNAP cassette}

The T7RNAP cassette was assembled from three pieces: a terminator (TM) piece, a T7RNAP piece, a CmR piece (Table S3). To transcriptionally isolate from the cassette a 5' terminator was designed upstream the T7RNAP piece. The strong synthetic terminator $\left(\right.$ L3S2P21 $^{[76]}$ was selected to avoid potential homology with native terminators during genomic insertion. The terminator was order was from IDT as a sense and antisense oligonucleotide (Table S2). The T7RNAP part was amplified from BL21(DE3) genomic DNA. The T7RNAP PCR was performed using Phusion with EDC408 and EDC323 primers, 5 ng genomic DNA per $\mu \mathrm{L}$ of PCR reaction, $3 \%$ DMSO at $98^{\circ} \mathrm{C}$ for $15 \mathrm{~min}$, with 30 cycles of $98^{\circ} \mathrm{C}$ for $30 \mathrm{~s}, 55^{\circ} \mathrm{C}$ for $30 \mathrm{~s}$, and 
$72^{\circ} \mathrm{C}$ for $3 \mathrm{~min}$, and a final extension of $72^{\circ} \mathrm{C}$ for $25 \mathrm{~min}$. The $\mathrm{CmR}$ piece PCR was performed using Phusion with EDC413 and EDC414 primers and the pAM552C plasmid ${ }^{[71]}$ at $98^{\circ} \mathrm{C}$ for 15 min, with 30 cycles of $98^{\circ} \mathrm{C}$ for $60 \mathrm{~s}, 55^{\circ} \mathrm{C}$ for $30 \mathrm{~s}$, and $72^{\circ} \mathrm{C}$ for $45 \mathrm{~s}$, and a final extension of $72^{\circ} \mathrm{C}$ for $25 \mathrm{~min}$. The T7RNAP and CmR PCR reactions each received $1 \mu \mathrm{L}$ of Dpnl per $20 \mu \mathrm{L}$ of PCR reaction and were incubated at $37^{\circ} \mathrm{C}$ for $2 \mathrm{hr}$. The PCR reactions were column purified and run on a $0.7 \%$ agarose gel at $90 \mathrm{~V}$ for $45 \mathrm{~min}$. The correct sized band was cut out of the gel and column purified. All three parts were then pool together at equal molar concentrations (75 ng of DNA total) in an overlap PCR reaction using Phusion, 3\% DMSO at $98^{\circ} \mathrm{C}$ for 10 min, with 15 cycles of $98^{\circ} \mathrm{C}$ for $30 \mathrm{~s}, 55^{\circ} \mathrm{C}$ for $30 \mathrm{~s}$, and $72^{\circ} \mathrm{C}$ for $4 \mathrm{~min}$, and a final extension of $72^{\circ} \mathrm{C}$ for 10 min. The overlap PCR was then diluted 20 -fold into a second PCR reaction with EDC410 and EDC414 primers at $98^{\circ} \mathrm{C}$ for $3 \mathrm{~min}$, with 24 cycles of $98^{\circ} \mathrm{C}$ for $30 \mathrm{~s}, 55^{\circ} \mathrm{C}$ for $30 \mathrm{~s}$, and $72^{\circ} \mathrm{C}$ for 4 min, and a final extension of $72^{\circ} \mathrm{C}$ for $10 \mathrm{~min}$. PCR reactions were then column purified and run on a $0.7 \%$ agarose gel at $90 \mathrm{~V}$ for $45 \mathrm{~min}$. The correct sized bands were cut out and column purified. Next, 45 bp of genomic insertion site homology was added to the 5' and 3' end of the assembled T7RNAP cassette using Phusion, 3\% DMSO with JGP139 and JGP140 primers at $98^{\circ} \mathrm{C}$ for $3 \mathrm{~min}$, with 25 cycles of $98^{\circ} \mathrm{C}$ for $60 \mathrm{~s}, 65^{\circ} \mathrm{C}$ for $30 \mathrm{~s}$, and $72^{\circ} \mathrm{C}$ for $7 \mathrm{~min}$, and a final extension of $72^{\circ} \mathrm{C}$ for $10 \mathrm{~min}$. PCR reactions were column purified, run on a $0.7 \%$ agarose gel at $90 \mathrm{~V}$ for $45 \mathrm{~min}$. The correct sized bands were cut out and column purified. The sequence of the fully assembled cassette was confirmed via sequencing.

\section{Datsenko-Wanner of T7RNAP cassette}

The T7RNAP cassette was inserted using the $\lambda$-red homologous recombination method for PCR products. ${ }^{[58,66]}$ The $C 321 . \Delta A$ strain contains the $\lambda$-red recombinase machinery on its genome which enables quick modification of the genome without scars. Briefly, $3 \mathrm{~mL}$ of LB-L media was inoculated with overnight culture of the strain of interest at a 1:50 dilution. Cultures 
were grown at $32^{\circ} \mathrm{C}, 250 \mathrm{rpm}$ until $\mathrm{OD}_{600}$ reached 0.7 as read on a Libra S4. The culture was heat shocked at $42^{\circ} \mathrm{C}$ for $15 \mathrm{~min}$ at $100 \mathrm{rpm}$ to activate expression of the $\lambda$-red recombinase machinery. Cultures were place on ice for at least 15 min to cool cells down, spinning the culture tube in ice every $3 \mathrm{~min}$. Next, $1 \mathrm{~mL}$ of culture was harvested and washed twice with ice-cold sterile deionized water, pelleting cells at $13,000 \mathrm{~g}$ at $4^{0} \mathrm{C}$. The cell pellets were resuspended with $10 \mathrm{ng}$ of the T7RNAP cassette in $100 \mu \mathrm{L}$ of ice-cold sterile deionized water and electroporated. Cells were then recovered in $1 \mathrm{~mL}$ LB-L for at least $3 \mathrm{hr}$ at $32^{\circ} \mathrm{C}, 250 \mathrm{rpm}$ and plated on $\mathrm{Cm}_{34}$ plates for $1-3$ days at $30^{\circ} \mathrm{C}$.

Screening for full T7RNAP cassette insertion

Cells that genomically inserted the $\mathrm{CmR}$ portion of the cassette grew on the $\mathrm{Cm}_{34}$ plates. To screen for full insertion of the cassette colony PCR was performed. Colonies on the $\mathrm{Cm}_{34}$ plate were picked and inoculated into $100 \mu \mathrm{L}$ LB-L $\mathrm{Cm}_{25}$ media in 96-well polystyrene plates (Costar 3370 ) incubated at $32^{\circ} \mathrm{C}, 250 \mathrm{rpm}$ for at least $3 \mathrm{hr}$. The cultures were used as the template in colony PCR reactions. To screen for 5' portion of T7RNAP a PCR reaction was performed with MASC PCR reactions using JGP173 and JGP292 primers at $95^{\circ} \mathrm{C}$ for 15 min, with 30 cycles of $95^{\circ} \mathrm{C}$ for $30 \mathrm{~s}, 52^{\circ} \mathrm{C}$ for $30 \mathrm{~s}$, and $72^{\circ} \mathrm{C}$ for $1 \mathrm{~min}$, and a final extension of $72^{\circ} \mathrm{C}$ for $10 \mathrm{~min}$. PCR reactions were run on a $2 \%$ gel, $110 \mathrm{~V} 45 \mathrm{~min}$. Colony PCR was repeated at a larger scale for the colonies that resulted in a band, reactions were column purified and submitted for sequencing using JGP173, EDC280 and JGP292 primers. Positive sequence hits were screened for the full T7RNAP region being inserted using Multiplex Master Mix with EDC282 and JGP153 primers at $95^{\circ} \mathrm{C}$ for $15 \mathrm{~min}$, with 30 cycles of $95^{\circ} \mathrm{C}$ for $30 \mathrm{~s}, 53^{\circ} \mathrm{C}$ for $30 \mathrm{~s}$, and $72^{\circ} \mathrm{C}$ for $1.5 \mathrm{~min}$, and a final extension of $72^{\circ} \mathrm{C}$ for $10 \mathrm{~min}$. The PCR reaction were run on a $2 \%$ agarose gel. Colony PCR was repeated at a larger scale for the colonies that resulted in a band. The reactions were column 
purified and submitted for sequencing using EDC282, EDC283, EDC284, EDC285, and JGP153 primers.

\section{Removing antibiotic resistance marker}

Clones with full T7RNAP cassette present then underwent MAGE to remove the CmR gene using a mutagenic oligonucleotide, JGP389, with homology on the 5' and 3' end of the CmR gene. After 8 cycles of MAGE, overnight cultures were plated on LB plates at $10^{-6}$ dilutions in LB$\mathrm{L} \mathrm{Cb}_{50}$ media. Colonies were replica-plated onto $\mathrm{LB}-\mathrm{Cb}_{100}$ and $\mathrm{LB} \mathrm{Cb}_{100} \mathrm{Cm}_{34}$ plates and incubated at $32^{\circ} \mathrm{C}$ overnight. Colonies that grew on LB-Cb 100 plates and not $\mathrm{LB}-\mathrm{Cb}_{100} \mathrm{Cm}_{34}$ plates underwent PCR using Multiplex Master Mix with EDC413 and JGP211 primers at $95^{\circ} \mathrm{C}$ for 15 min, with 30 cycles of $95^{\circ} \mathrm{C}$ for $30 \mathrm{~s}, 54^{\circ} \mathrm{C}$ for $30 \mathrm{~s}$, and $72^{\circ} \mathrm{C}$ for $1.5 \mathrm{~min}$, and a final extension of $72^{\circ} \mathrm{C}$ for 10 min. For positive hits colonies the PCR reactions were repeated at a larger scale, column purified and submitted to sequencing with EDC413 and JGP211 primers to confirm the CmR gene was completely removed.

\section{Full-length sfGFP purification and quantification}

Strains were freshly transformed with the plasmids of interest. A single colony was inoculated into $5 \mathrm{~mL}$ of $2 \mathrm{X} \mathrm{YT}$ media with $\mathrm{Kan}_{35} \mathrm{Cm}_{25}$ and grown overnight at $32^{\circ} \mathrm{C}$ at $250 \mathrm{rpm}$. Overnight cultures were diluted 1:50 into $40 \mathrm{~mL}$ of fresh $2 \mathrm{X}$ YT media $\mathrm{Kan}_{35} \mathrm{Cm}_{25}$ and grown at $32^{\circ} \mathrm{C}, 250 \mathrm{rpm} . \mathrm{OD}_{600}$ was monitored on a NanoDrop 2000c until $\mathrm{OD}_{600}$ 0.6-0.8 at which point cultures were induced with $5 \mathrm{mM}$ ncAA, $1 \mathrm{mM}$ IPTG, and $0.02 \%$ arabinose. Cultures were harvested after $20 \mathrm{hr}$ after induction by pelleting $30 \mathrm{~mL}$ of culture at $5,000 \mathrm{~g}$ for $10 \mathrm{~min}$ at $4^{\circ} \mathrm{C}$. The pellet was resuspended in $0.8 \mathrm{~mL}$ of $1 \mathrm{X}$ phosphate-buffered saline (PBS) buffer for every 1 $\mathrm{g}$ of wet cell pellet. Cells were lysed at a frequency of $20 \mathrm{kHz}$ and an amplitude of $50 \%$ using a Q125 Sonicator (Qsonica, Newton, CT, USA) with a $3.75 \mathrm{~mm}$ diameter probe ${ }^{[77]}$ for 5 cycles of 
45 s sonication and 59 s sitting on ice. The input energy (Joules) per cycle averaged to 274 . Lysed samples were then centrifuged at $21,000 \mathrm{rpm}$ for $10 \mathrm{~min}$ at $4^{\circ} \mathrm{C}$. Supernatant was collected as the soluble fraction. Full-length sfGFP was purified from the soluble fraction by using a C-terminal strep-tag and $0.2 \mathrm{~mL}$ gratify-flow Strep-Tactin Sepharose mini-columns (IBA GmbH, Gottingen, DEU). Purified sfGFP was measured using a Quick Start Bradford Kit (BioRad, Hercules, CA, USA) in biological triplicate and technical triplicate.

\section{Associated Content}

The Supplemental Information:

Supplemental Table 1. Quantification of in vivo protein concentrations of top mutant strains; Supplemental Figure 1. Construction of the T7RNAP cassette; Supplemental Figure 2. Expression of sfGFP in top C321. $\triangle A$ mutants containing genomically expressed T7RNAP cassette; Supplemental Figure 3. Expression of sfGFP in C321. $\triangle A$ T7 strains using a pET reporter plasmid; Supplemental Figure 4. Expression of sfGFP in C321. $\triangle A-T 7$ strains produced by first inserting T7RNAP, followed by the introduction of protein and nuclease mutations; Supplemental Figure 5. Expression of sfGFP-2UAG utilizing the pyrrolysine orthogonal translation system in $\beta$ strains; Supplemental Table 2. Oligonucleotides used in this study; Supplemental Table 3. T7RNAP cassette parts.

\section{Author Information}

Corresponding Author: m-jewett@northwestern.edu

J.G.P and E.D.C constructed the strains. E.D.C designed the T7RNAP cassette. J.G.P, O.W. and E.D.C. constructed, introduced and verified T7RNAP genomic insertion. J.G.P, E.D.C and M.C.J. designed experiments. J.G.P. and E.D.C. performed the experiments. J.G.P. and M.C.J. wrote 
the manuscript. All authors discussed the results and commented on the manuscript. M.C.J. has a financial interest in Pearl Bio. M.C.J.'s interests are reviewed and managed by Northwestern University in accordance with their conflict of interest policies. All other authors declare no conflicts of interest.

\section{Acknowledgements}

This work was supported by the National Science Foundation (NSF) (MCB-1716766), the Office of Naval Research (N00014-11-1-0363), the Army Research Office (W911NF-20-1-0195, W911NF-18-1-0200), the Human Frontiers Science Program. RGP0015/2017, and the David and Lucile Packard Foundation (2011-37152), and the NIH Initiative for Maximizing Student Development (IMSD) (PAR-17-053). The authors would like to thank Professor Joshua Leonard for his critical review of the manuscript and Professor Peter G. Schultz for providing the pEVOL plasmid.

\section{References}

1. Lodish, H., Berk, A., Zipursky, S. L., Matsudaira, P., Baltimore, D., \& Darnell, J. (2000). Molecular Cell Biology (4th ed.). W. H. Freeman.

2. Macino, G., Coruzzi, G., Nobrega, F. G., Li, M., \& Tzagoloff, A. (1979). Use of the UGA terminator as a tryptophan codon in yeast mitochondria. Proceedings of the National Academy of Sciences of the United States of America, 76(8), 3784-3785. https://doi.org/10.1073/pnas.76.8.3784

3. Ambrogelly, A., Palioura, S., \& Söll, D. (2007). Natural expansion of the genetic code. Nature Chemical Biology, 3(1), 29-35. https://doi.org/10.1038/nchembio847

4. Arranz-Gibert, P., Vanderschuren, K., \& Isaacs, F. (2018). Next-Generation Genetic Code Expansion. Current Opinion in Chemical Biology, 46, 203-211. https://doi.org/10.1016/j.cbpa.2018.07.020 
5. Bogart, J. W., Cabezas, M. D., Vögeli, B., Wong, D. A., Karim, A. S., \& Jewett, M. C. (2021). Cell-Free Exploration of the Natural Product Chemical Space. Chembiochem: A European Journal of Chemical Biology, 22(1), 84-91. https://doi.org/10.1002/cbic.202000452

6. Chin, J. W. (2017). Expanding and reprogramming the genetic code. Nature, 550(7674), 5360. https://doi.org/10.1038/nature24031

7. Hammerling, M. J., Krüger, A., \& Jewett, M. C. (2020). Strategies for in vitro engineering of the translation machinery. Nucleic Acids Research, 48(3), 1068-1083. https://doi.org/10.1093/nar/gkz1011

8. Tharp, J. M., Krahn, N., Varshney, U., \& Söll, D. (2020). Hijacking Translation Initiation for Synthetic Biology. $\quad$ ChemBioChem, 21(10), 1387-1396. https://doi.org/10.1002/cbic.202000017

9. Rosano, G. L., \& Ceccarelli, E. A. (2014). Recombinant protein expression in Escherichia coli: Advances and challenges. Frontiers in Microbiology, 5, 172. https://doi.org/10.3389/fmicb.2014.00172

10. Albericio, F. (2000). Solid-Phase Synthesis: A Practical Guide (1st ed.). CRC Press.

11. DI, B., Da, D., \& Ha, L. (2003). Unnatural amino acid mutagenesis in mapping ion channel function. Current Opinion in Neurobiology, 13(3), 264-270. https://doi.org/10.1016/s09594388(03)00068-0

12. Cornish, V., Mendel, D., \& Schultz, P. (1995). Probing Protein Structure and Function with an Expanded Genetic Code. Angewandte Chemie International Edition in English, 34(6), $621-633$.

13. Yu, Y., Zhou, Q., Wang, L., Liu, X., Zhang, W., Hu, M., Dong, J., Li, J., Lv, X., Ouyang, H., Li, H., Gao, F., Gong, W., Lu, Y., \& Wang, J. (2015). Significant improvement of oxidase activity through the genetic incorporation of a redox-active unnatural amino acid. Chemical Science, 6(7), 3881-3885. https://doi.org/10.1039/C5SC01126D 
14. Liu, H., Wang, L., Brock, A., Wong, C.-H., \& Schultz, P. G. (2003). A method for the generation of glycoprotein mimetics. Journal of the American Chemical Society, 125(7), 1702-1703. https://doi.org/10.1021/ja029433n

15. Oza, J. P., Aerni, H. R., Pirman, N. L., Barber, K. W., ter Haar, C. M., Rogulina, S., Amrofell, M. B., Isaacs, F. J., Rinehart, J., \& Jewett, M. C. (2015). Robust production of recombinant phosphoproteins using cell-free protein synthesis. Nature Communications, 6(1), 8168. https://doi.org/10.1038/ncomms9168

16. Pirman, N. L., Barber, K. W., Aerni, H. R., Ma, N. J., Haimovich, A. D., Rogulina, S., Isaacs, F. J., \& Rinehart, J. (2015). A flexible codon in genomically recoded Escherichia coli permits programmable protein phosphorylation. Nature Communications, 6(1), 8130. https://doi.org/10.1038/ncomms9130

17. Hammerling, M. J., Ellefson, J. W., Boutz, D. R., Marcotte, E. M., Ellington, A. D., \& Barrick, J. E. (2014). Bacteriophages use an expanded genetic code on evolutionary paths to higher fitness. Nature Chemical Biology, 10(3), 178-180. https://doi.org/10.1038/nchembio. 1450

18. O’Donoghue, P., Ling, J., Wang, Y.-S., \& Söll, D. (2013). Upgrading protein synthesis for synthetic biology. Nature Chemical Biology, 9(10), 594-598. https://doi.org/10.1038/nchembio.1339

19. Soye, B. J. D., Patel, J. R., Isaacs, F. J., \& Jewett, M. C. (2015). Repurposing the translation apparatus for synthetic biology. Current Opinion in Chemical Biology, 28, 83-90. https://doi.org/10.1016/j.cbpa.2015.06.008

20. Katoh, T., Sengoku, T., Hirata, K., Ogata, K., \& Suga, H. (2020). Ribosomal synthesis and de novo discovery of bioactive foldamer peptides containing cyclic $\beta$-amino acids. Nature Chemistry, 12(11), 1081-1088. https://doi.org/10.1038/s41557-020-0525-1 
21. Katoh, T., \& Suga, H. (2020). Ribosomal Elongation of Cyclic y-Amino Acids using a Reprogrammed Genetic Code. Journal of the American Chemical Society, 142(11), 49654969. https://doi.org/10.1021/jacs.9b12280

22. Katoh, T., Tajima, K., \& Suga, H. (2017). Consecutive Elongation of D-Amino Acids in Translation. Cell Chemical Biology, 24(1), 46-54. https://doi.org/10.1016/j.chembiol.2016.11.012

23. Fujino, T., Goto, Y., Suga, H., \& Murakami, H. (2016). Ribosomal Synthesis of Peptides with Multiple ß-Amino Acids. Journal of the American Chemical Society, 138(6), 1962-1969. https://doi.org/10.1021/jacs.5b12482

24. Lee, J., Schwarz, K. J., Yu, H., Krüger, A., Anslyn, E. V., Ellington, A. D., Moore, J. S., \& Jewett, M. C. (2021). Ribosome-mediated incorporation of fluorescent amino acids into peptides in vitro. Chemical Communications, 57(21), 2661-2664. https://doi.org/10.1039/D0CC07740B

25. Lee, J., Schwarz, K. J., Kim, D. S., Moore, J. S., \& Jewett, M. C. (2020). Ribosome-mediated polymerization of long chain carbon and cyclic amino acids into peptides in vitro. Nature Communications, 11(1), 4304. https://doi.org/10.1038/s41467-020-18001-x

26. Lee, J., Schwieter, K. E., Watkins, A. M., Kim, D. S., Yu, H., Schwarz, K. J., Lim, J., Coronado, J., Byrom, M., Anslyn, E. V., Ellington, A. D., Moore, J. S., \& Jewett, M. C. (2019). Expanding the limits of the second genetic code with ribozymes. Nature Communications, 10(1), 5097. https://doi.org/10.1038/s41467-019-12916-w

27. Lee, J., Torres, R., Kim, D. S., Byrom, M., Ellington, A. D., \& Jewett, M. C. (2020). Ribosomal incorporation of cyclic $\beta$-amino acids into peptides using in vitro translation. Chemical Communications, 56(42), 5597-5600. https://doi.org/10.1039/D0CC02121K

28. Rogers, J. M., Kwon, S., Dawson, S. J., Mandal, P. K., Suga, H., \& Huc, I. (2018). Ribosomal synthesis and folding of peptide-helical aromatic foldamer hybrids. Nature Chemistry, 10(4), 405-412. https://doi.org/10.1038/s41557-018-0007-x 
29. Takatsuji, R., Shinbara, K., Katoh, T., Goto, Y., Passioura, T., Yajima, R., Komatsu, Y., \& Suga, H. (2019). Ribosomal Synthesis of Backbone-Cyclic Peptides Compatible with In Vitro Display. Journal of the American Chemical Society, 141(6), 2279-2287. https://doi.org/10.1021/jacs.8b05327

30. Kakkar, N., Perez, J. G., Liu, W. R., Jewett, M. C., \& van der Donk, W. A. (2018). Incorporation of Nonproteinogenic Amino Acids in Class I and II Lantibiotics. ACS Chemical Biology, 13(4), 951-957. https://doi.org/10.1021/acschembio.7b01024

31. Ryu, Y., \& Schultz, P. G. (2006). Efficient incorporation of unnatural amino acids into proteins in Escherichia coli. Nature Methods, 3(4), 263-265. https://doi.org/10.1038/nmeth864

32. Santoro, S. W., Wang, L., Herberich, B., King, D. S., \& Schultz, P. G. (2002). An efficient system for the evolution of aminoacyl-tRNA synthetase specificity. Nature Biotechnology, 20(10), 1044-1048. https://doi.org/10.1038/nbt742

33. Young, T. S., Ahmad, I., Yin, J. A., \& Schultz, P. G. (2010). An enhanced system for unnatural amino acid mutagenesis in E. coli. Journal of Molecular Biology, 395(2), 361-374. https://doi.org/10.1016/j.jmb.2009.10.030

34. Griffiths, A., Doebley, J., Peichel, C., \& Wassarman, D. (2020). Introduction to Genetic Analysis (12th ed.). Macmillan.

35. Isaacs, F. J., Carr, P. A., Wang, H. H., Lajoie, M. J., Sterling, B., Kraal, L., Tolonen, A. C., Gianoulis, T. A., Goodman, D. B., Reppas, N. B., Emig, C. J., Bang, D., Hwang, S. J., Jewett, M. C., Jacobson, J. M., \& Church, G. M. (2011). Precise manipulation of chromosomes in vivo enables genome-wide codon replacement. Science, 333(6040), 348-353. https://doi.org/10.1126/science.1205822

36. Robertson, W. E., Funke, L. F. H., de la Torre, D., Fredens, J., Elliott, T. S., Spinck, M., Christova, Y., Cervettini, D., Böge, F. L., Liu, K. C., Buse, S., Maslen, S., Salmond, G. P. C., \& Chin, J. W. (2021). Sense codon reassignment enables viral resistance and encoded 
polymer synthesis. Science (New York, N.Y.), 372(6546), 1057-1062. https://doi.org/10.1126/science.abg3029

37. Fredens, J., Wang, K., de la Torre, D., Funke, L. F. H., Robertson, W. E., Christova, Y., Chia, T., Schmied, W. H., Dunkelmann, D. L., Beránek, V., Uttamapinant, C., Llamazares, A. G., Elliott, T. S., \& Chin, J. W. (2019). Total synthesis of Escherichia coli with a recoded genome. Nature, 569(7757), 514-518. https://doi.org/10.1038/s41586-019-1192-5

38. Hong, S. H., Kwon, Y.-C., Martin, R. W., Des Soye, B. J., de Paz, A. M., Swonger, K. N., Ntai, I., Kelleher, N. L., \& Jewett, M. C. (2015). Improving cell-free protein synthesis through genome engineering of Escherichia coli lacking release factor 1. Chembiochem: $A$ European Journal of Chemical Biology, 16(5), 844-853. https://doi.org/10.1002/cbic.201402708

39. Amiram, M., Haimovich, A. D., Fan, C., Wang, Y.-S., Aerni, H.-R., Ntai, I., Moonan, D. W., Ma, N. J., Rovner, A. J., Hong, S. H., Kelleher, N. L., Goodman, A. L., Jewett, M. C., Söll, D., Rinehart, J., \& Isaacs, F. J. (2015). Evolution of translation machinery in recoded bacteria enables multi-site incorporation of nonstandard amino acids. Nature Biotechnology, 33(12), 1272-1279. https://doi.org/10.1038/nbt.3372

40. Mandell, D. J., Lajoie, M. J., Mee, M. T., Takeuchi, R., Kuznetsov, G., Norville, J. E., Gregg, C. J., Stoddard, B. L., \& Church, G. M. (2015). Biocontainment of genetically modified organisms by synthetic protein design. Nature, 518(7537), 55-60. https://doi.org/10.1038/nature14121

41. Gopal, G. J., \& Kumar, A. (2013). Strategies for the production of recombinant protein in Escherichia coli. The Protein Journal, 32(6), 419-425. https://doi.org/10.1007/s10930013-9502-5

42. Makino, T., Skretas, G., \& Georgiou, G. (2011). Strain engineering for improved expression of recombinant proteins in bacteria. Microbial Cell Factories, 10, 32. https://doi.org/10.1186/1475-2859-10-32 
43. Martin, R. W., Des Soye, B. J., Kwon, Y.-C., Kay, J., Davis, R. G., Thomas, P. M., Majewska, N. I., Chen, C. X., Marcum, R. D., Weiss, M. G., Stoddart, A. E., Amiram, M., Ranji Charna, A. K., Patel, J. R., Isaacs, F. J., Kelleher, N. L., Hong, S. H., \& Jewett, M. C. (2018). Cellfree protein synthesis from genomically recoded bacteria enables multisite incorporation of noncanonical amino acids. Nature Communications, 9(1), 1203. https://doi.org/10.1038/s41467-018-03469-5

44. Borja, G. M., Meza Mora, E., Barrón, B., Gosset, G., Ramírez, O. T., \& Lara, A. R. (2012). Engineering Escherichia coli to increase plasmid DNA production in high cell-density cultivations in batch mode. Microbial Cell Factories, 11(1), 132. https://doi.org/10.1186/1475-2859-11-132

45. Lopez, P. J., Marchand, I., Joyce, S. A., \& Dreyfus, M. (1999). The C-terminal half of RNase E, which organizes the Escherichia coli degradosome, participates in mRNA degradation but not rRNA processing in vivo. Molecular Microbiology, 33(1), 188-199. https://doi.org/10.1046/j.1365-2958.1999.01465.x

46. Kaplan, R., \& Apirion, D. (1974). The involvement of ribonuclease I, ribonuclease II, and polynucleotide phosphorylase in the degradation of stable ribonucleic acid during carbon starvation in Escherichia coli. The Journal of Biological Chemistry, 249(1), 149-151.

47. Deutscher, M. P. (1985). E. coli RNases: Making sense of alphabet soup. Cell, 40(4), 731732. https://doi.org/10.1016/0092-8674(85)90330-7

48. Studier, F. W., \& Moffatt, B. A. (1986). Use of bacteriophage T7 RNA polymerase to direct selective high-level expression of cloned genes. Journal of Molecular Biology, 189(1), 113-130. https://doi.org/10.1016/0022-2836(86)90385-2

49. Baneyx, F. (1999). Recombinant protein expression in Escherichia coli. Current Opinion in Biotechnology, 10(5), 411-421. https://doi.org/10.1016/s0958-1669(99)00003-8 
50. Graumann, K., \& Premstaller, A. (2006). Manufacturing of recombinant therapeutic proteins in microbial systems. Biotechnology Journal, 1(2), 164-186. https://doi.org/10.1002/biot.200500051

51. Wang, H. H., Isaacs, F. J., Carr, P. A., Sun, Z. Z., Xu, G., Forest, C. R., \& Church, G. M. (2009). Programming cells by multiplex genome engineering and accelerated evolution. Nature, 460(7257), 894-898. https://doi.org/10.1038/nature08187

52. saiSree, L., Reddy, M., \& Gowrishankar, J. (2001). IS186 insertion at a hot spot in the lon promoter as a basis for lon protease deficiency of Escherichia coli B: Identification of a consensus target sequence for IS186 transposition. Journal of Bacteriology, 183(23), 6943-6946. https://doi.org/10.1128/JB.183.23.6943-6946.2001

53. Goerke, A., \& Swartz, J. (2008). Cell-Free Synthesis of Proteins Containing Unnatural Amino $\begin{array}{lll}\text { Acids (Patent No-2008066583-A3). } & \text { No. WO }\end{array}$ https://patentscope.wipo.int/search/en/detail.jsf?docld=WO2008066583

54. Spiess, C., Beil, A., \& Ehrmann, M. (1999). A temperature-dependent switch from chaperone to protease in a widely conserved heat shock protein. Cell, 97(3), 339-347. https://doi.org/10.1016/s0092-8674(00)80743-6

55. Kido, M., Yamanaka, K., Mitani, T., Niki, H., Ogura, T., \& Hiraga, S. (1996). RNase E polypeptides lacking a carboxyl-terminal half suppress a mukB mutation in Escherichia coli. Journal of Bacteriology, 178(13), 3917-3925. https://doi.org/10.1128/jb.178.13.39173925.1996

56. Donovan, W. P., \& Kushner, S. R. (1986). Polynucleotide phosphorylase and ribonuclease II are required for cell viability and mRNA turnover in Escherichia coli K-12. Proceedings of the National Academy of Sciences of the United States of America, 83(1), 120-124. https://doi.org/10.1073/pnas.83.1.120 
57. Bermardo, G., \& Cordonnier, C. (1965). Mechanism of degration of DNA by endronuclease from Escherichia Coli. Journal of Molecular Biology, 11, 141-143. https://doi.org/10.1016/s0022-2836(65)80180-2

58. Wang, H. H., \& Church, G. M. (2011). Multiplexed genome engineering and genotyping methods applications for synthetic biology and metabolic engineering. Methods in Enzymology, 498, 409-426. https://doi.org/10.1016/B978-0-12-385120-8.00018-8

59. Kushner, S. R. (2002). MRNA Decay in Escherichia coli Comes of Age. Journal of Bacteriology, 184(17), 4658-4665. https://doi.org/10.1128/JB.184.17.4658-4665.2002

60. Studier, F. W., Daegelen, P., Lenski, R. E., Maslov, S., \& Kim, J. F. (2009). Understanding the differences between genome sequences of Escherichia coli B strains REL606 and BL21(DE3) and comparison of the E. coli B and K-12 genomes. Journal of Molecular Biology, 394(4), 653-680. https://doi.org/10.1016/j.jmb.2009.09.021

61. Inouye, S., \& Inouye, M. (1985). Up-promoter mutations in the Ipp gene of Escherichia coli. Nucleic Acids Research, 13(9), 3101-3110.

62. Srinivasan, G., James, C. M., \& Krzycki, J. A. (2002). Pyrrolysine encoded by UAG in Archaea: Charging of a UAG-decoding specialized tRNA. Science (New York, N.Y.), 296(5572), 1459-1462. https://doi.org/10.1126/science.1069588

63. Yanagisawa, T., Ishii, R., Fukunaga, R., Nureki, O., \& Yokoyama, S. (2006). Crystallization and preliminary X-ray crystallographic analysis of the catalytic domain of pyrrolysyl-tRNA synthetase from the methanogenic archaeon Methanosarcina mazei. Acta Crystallographica. Section F, Structural Biology and Crystallization Communications, 62(Pt 10), 1031-1033. https://doi.org/10.1107/S1744309106036700

64. Jiang, R., \& Krzycki, J. A. (2012). PylSn and the homologous N-terminal domain of pyrrolysyltRNA synthetase bind the tRNA that is essential for the genetic encoding of pyrrolysine. The Journal of Biological Chemistry, 287(39), 32738-32746. https://doi.org/10.1074/jbc.M112.396754 
65. Hao, B., Zhao, G., Kang, P. T., Soares, J. A., Ferguson, T. K., Gallucci, J., Krzycki, J. A., \& Chan, M. K. (2004). Reactivity and Chemical Synthesis of L-Pyrrolysine-The 22nd Genetically Encoded Amino Acid. Chemistry \& Biology, 11(9), 1317-1324. https://doi.org/10.1016/j.chembiol.2004.07.011

66. Datsenko, K. A., \& Wanner, B. L. (2000). One-step inactivation of chromosomal genes in Escherichia coli K-12 using PCR products. Proceedings of the National Academy of Sciences of the United States of America, 97(12), 6640-6645. https://doi.org/10.1073/pnas.120163297

67. Reim, R. L., Narula, S. K., Ryan, M. J., \& Leibowitz, P. J. (1991). Novel expression systems utilizing bacteriophage $t 7$ promoters and gene sequences (Patent No. AU7043491A). https://patents.google.com/patent/AU7043491A/en

68. Aleksashin, N. A., Leppik, M., Hockenberry, A. J., Klepacki, D., Vázquez-Laslop, N., Jewett, M. C., Remme, J., \& Mankin, A. S. (2019). Assembly and functionality of the ribosome $\begin{array}{llll}\text { with thered } \quad \text { subunits. Nature Communications, } & \text { 10(1), }\end{array}$ https://doi.org/10.1038/s41467-019-08892-w

69. Yesselman, J. D., Eiler, D., Carlson, E. D., Gotrik, M. R., d’Aquino, A. E., Ooms, A. N., Kladwang, W., Carlson, P. D., Shi, X., Costantino, D. A., Herschlag, D., Lucks, J. B., Jewett, M. C., Kieft, J. S., \& Das, R. (2019). Computational design of three-dimensional RNA structure and function. Nature Nanotechnology, 14(9), 866-873. https://doi.org/10.1038/s41565-019-0517-8

70. Aleksashin, N. A., Szal, T., d’Aquino, A. E., Jewett, M. C., Vázquez-Laslop, N., \& Mankin, A. S. (2020). A fully orthogonal system for protein synthesis in bacterial cells. Nature Communications, 11(1), 1858. https://doi.org/10.1038/s41467-020-15756-1

71. Orelle, C., Carlson, E. D., Szal, T., Florin, T., Jewett, M. C., \& Mankin, A. S. (2015). Protein synthesis by ribosomes with tethered subunits. Nature, 524(7563), 119-124. https://doi.org/10.1038/nature14862 
72. Carlson, E. D., d’Aquino, A. E., Kim, D. S., Fulk, E. M., Hoang, K., Szal, T., Mankin, A. S., \& Jewett, M. C. (2019). Engineered ribosomes with tethered subunits for expanding biological function. Nature Communications, 10(1), 3920. https://doi.org/10.1038/s41467019-11427-y

73. Gibson, D. G., Young, L., Chuang, R.-Y., Venter, J. C., Hutchison, C. A., \& Smith, H. O. (2009). Enzymatic assembly of DNA molecules up to several hundred kilobases. Nature Methods, 6(5), 343-345. https://doi.org/10.1038/nmeth.1318

74. Gan, R., Perez, J. G., Carlson, E. D., Ntai, I., Isaacs, F. J., Kelleher, N. L., \& Jewett, M. C. (2017). Translation system engineering in Escherichia coli enhances non-canonical amino acid incorporation into proteins. Biotechnology and Bioengineering, 114(5), 1074-1086. https://doi.org/10.1002/bit.26239

75. Lajoie, M. J., Rovner, A. J., Goodman, D. B., Aerni, H.-R., Haimovich, A. D., Kuznetsov, G., Mercer, J. A., Wang, H. H., Carr, P. A., Mosberg, J. A., Rohland, N., Schultz, P. G., Jacobson, J. M., Rinehart, J., Church, G. M., \& Isaacs, F. J. (2013). Genomically Recoded Organisms Expand Biological Functions. Science (New York, N.Y.), 342(6156), 357-360. https://doi.org/10.1126/science.1241459

76. Chen, Y.-J., Liu, P., Nielsen, A. A. K., Brophy, J. A. N., Clancy, K., Peterson, T., \& Voigt, C. A. (2013). Characterization of 582 natural and synthetic terminators and quantification of their design constraints. Nature Methods, 10(7), 659-664. https://doi.org/10.1038/nmeth.2515

77. Kwon, Y.-C., \& Jewett, M. C. (2015). High-throughput preparation methods of crude extract for robust cell-free protein synthesis. Scientific Reports, 5(1), 8663. https://doi.org/10.1038/srep08663 


\title{
Supplementary Information for
}

\section{Improving genomically recoded Escherichia coli for the production of proteins containing non-canonical amino acids}

\author{
Jessica G. Perez ${ }^{1,2}$, Erik D. Carlson ${ }^{1,2}$, Oliver Weisser, and Michael C. Jewett ${ }^{1,2,3,4^{*}}$
}

${ }^{1}$ Department of Chemical and Biological Engineering, Northwestern University, Evanston, IL 60208, USA

${ }^{2}$ Chemistry of Life Processes Institute, Northwestern University, Evanston, IL 60208, USA

${ }^{3}$ Center for Synthetic Biology, Northwestern University, Evanston, IL 60208, USA

${ }^{4}$ Simpson Querrey Institute, Northwestern University, Chicago, IL 60611, USA

${ }^{*}$ Corresponding author:

Prof. Michael C. Jewett

2145 Sheridan Road, Tech E-136

Evanston, IL 60208-3120

m-jewett@northwestern.edu

Tel: (+1) 847467 5007; Fax (+1) 8474913728

\section{Contents:}

Tables 1-3

Figures 1-5 
bioRxiv preprint doi: https://doi.org/10.1101/2021.12.10.472167; this version posted December 11,2021 . The copyright holder for this preprint (which was not certified by peer review) is the author/funder, who has granted bioRxiv a license to display the preprint in perpetuity. It is made available under aCC-BY-NC-ND 4.0 International license.

Supplemental Table 1. Quantification of in vivo protein concentrations of top mutant strains.

\begin{tabular}{cccc}
\hline Strain & Reporter Plasmid & OTS Plasmid & $\boldsymbol{\mu g} / \mathbf{m L}$ \\
\hline$C 321 . \Delta A$ & pLpp5-sfGFP-wt & pEVOLpAzF & $389.4 \pm 72$ \\
\hline end $A^{-} r n e^{-}$ & pLpp5-sfGFP-wt & pEVOLpAzF & $757.4 \pm$ \\
ompT $T^{-}$ & & & 137 \\
\hline$C 321 . \Delta A$ & pLpp5-sfGFP-2TAG & pEVOLpAzF & $18 \pm 0.5$ \\
\hline end $A^{-} r n e^{-}$ & pLpp5-sfGFP-2TAG & pEVOLpAzF & $67 \pm 3.8$ \\
\hline
\end{tabular}


Supplemental Table 2. Oligonucleotides used in this study.

\begin{tabular}{|c|c|}
\hline MAGE Primers & Nucleotide Sequence \\
\hline $\begin{array}{l}\text { JGP290_endA- } \\
\text { MAGE }\end{array}$ & $\begin{array}{l}C^{*} G^{*} G * T^{*} \text { AAAAGTCCACGCTGACGCGCCCGGTACGTTTTATTGCTAAC } \\
\text { TGAAAAATTAACTGGCAGGGCAAAAAAGGCGTTGTTGATCTGCA }\end{array}$ \\
\hline $\begin{array}{l}\text { JGP287_rne13 } \\
\text { 1-MAGE }\end{array}$ & $\begin{array}{l}\mathrm{C}^{*} T^{*} \mathrm{G}^{*} T^{*} \text { TGAGCCGCTTCTTCGGCGCACTGAAAGCGCTGTTCAGCTAA } \\
\text { CTGAGAAGAAACCAAACCGACCGAGAACCAGCACCGAAAGCAGA }\end{array}$ \\
\hline $\begin{array}{l}\text { JGP286_rnb- } \\
\text { MAGE }\end{array}$ & $\begin{array}{l}\text { A*T*T*T*TGTCACCATCGACAGTGCCAGCACAGAAGATATGGATTAACT } \\
\text { GACTTTTCGCTAAGGCGTTGCCGGATGACAAACTTCAGCTGAT }\end{array}$ \\
\hline $\begin{array}{l}\text { JGP368_lonpro } \\
\text { m-MAGE }\end{array}$ & $\begin{array}{l}C^{*} A^{*} G^{*} A^{*} \text { TGACACGACTGTGCTTCACGCCATCTATTAACATGTACGTCA } \\
\text { GATAGAGGAAAATTAAAGGGGAGAAAATCCCCCTTTTGG }\end{array}$ \\
\hline ompT-MAGE & $\begin{array}{l}T^{*} G^{*} G^{*} A^{*} C A A C T C T C G G C A G C C G A G G T G G C A A T A T G G T C G C G C A G G A \\
\text { CTGGATGGATTCCAGTAACCCCGGAACCTGGACGGATGAAAGTAGA }\end{array}$ \\
\hline
\end{tabular}

\begin{tabular}{|c|c|}
\hline $\begin{array}{l}\text { MASC } \\
\text { Sequencing } \\
\text { Primers }\end{array}$ & Nucleotide Sequence \\
\hline $\begin{array}{l}\text { JGP362_endA- } \\
\text { wt-f }\end{array}$ & CCCGGTACGTTTTATTGCGGATGT \\
\hline $\begin{array}{l}\text { JGP363_endA- } \\
\text { mut-f }\end{array}$ & CCCGGTACGTTTTATTGCTAACTGA \\
\hline JGP364_end-r & GCTGGCGCTGGTAATTTCGGCGTCA \\
\hline end-seq-f & ATGTACCGTTATTTGTCTATTGCTGC \\
\hline $\begin{array}{l}\text { JGP346_rne- } \\
\text { wt-f }\end{array}$ & CACTGAAAGCGCTGTTCAGCGGTGGT \\
\hline $\begin{array}{l}\text { JGP347_rne- } \\
\text { mut-f }\end{array}$ & CACTGAAAGCGCTGTTCAGCTAACTGA \\
\hline JGP348_rne-r & GTGCGACTACCGCTTCTTCGGCTAC \\
\hline $\begin{array}{l}\text { JGP349_rne- } \\
\text { seq }\end{array}$ & CAGATGGAAACCCCGCACTACCACG \\
\hline $\begin{array}{l}\text { JGP359_rnb- } \\
\text { wt-f }\end{array}$ & CCAGCACAGAAGATATGGATGACGCC \\
\hline $\begin{array}{l}\text { JGP360_rnb- } \\
\text { mut-f }\end{array}$ & CCAGCACAGAAGATATGGATTAACTGA \\
\hline JGP361_rnb-r & TCACTTTCAGGCTGCCAGTCACCGG \\
\hline rnb-seq & CTGAAAGGCGATCGTTCTTTCTATG \\
\hline $\begin{array}{l}\text { JGP370_lon-wt- } \\
\mathrm{f}\end{array}$ & СТTTAАТTTTTССТСТАТTСТCG \\
\hline JGP371_Ion-f & GATTGCAGTACGCACCAGC \\
\hline $\begin{array}{l}\text { JGP369_lon- } \\
\text { seq }\end{array}$ & CTGCGTTCCATCGTAGAAGC \\
\hline $\begin{array}{l}\text { JGP365_ompT- } \\
\text { wt-f }\end{array}$ & CAGCCGAGGTGGCAATATGGTCGAT \\
\hline $\begin{array}{l}\text { JGP366_ompT- } \\
\text { mut-f }\end{array}$ & CAGCCGAGGTGGCAATATGGTCGCG \\
\hline $\begin{array}{l}\text { JGP367_ompT- } \\
\mathrm{r}\end{array}$ & GAGTTCAAAATCTTCATAACGATAAC \\
\hline $\begin{array}{l}\text { JGP345_ompT- } \\
\text { seq-f }\end{array}$ & CTGACAACCCCTATTGCGATCAGCTC \\
\hline
\end{tabular}




\begin{tabular}{|c|c|}
\hline $\begin{array}{l}\text { T7RNAP } \\
\text { cassette } \\
\text { construction }\end{array}$ & Nucleotide Sequence \\
\hline $\begin{array}{l}\text { JGP221_L3S2P } \\
\text { 21_sense }\end{array}$ & $\begin{array}{l}\text { GAT TTT CAG CCT GAT ACA GCT CGG TAC CAA ATT CCA GAA AAG } \\
\text { AGG CCT CCC GAA AGG GGG GCC TTT TTT CGT TTT GGT CCC CTT } \\
\text { TTT GCG TTT CTA CA }\end{array}$ \\
\hline $\begin{array}{l}\text { JGP221_L3S2P } \\
\text { 21_antisense }\end{array}$ & $\begin{array}{l}\text { TGTAGAAACGCAAAAAGGGGACCAAAACGAAAAAAGGCCCCCCTTTC } \\
\text { GGGAGGCCTCTTTTCTGGAATTTGGTACCGAGCTGTATCAGGCTGAA } \\
\text { AATC }\end{array}$ \\
\hline $\begin{array}{l}\text { EDC408_DE3- } \\
0-f\end{array}$ & GCTTTTTTATACTAAGTTGGCATTATAAAAAAG \\
\hline $\begin{array}{l}\text { EDC323_iT739 } \\
6-r\end{array}$ & GACTTACGGCTGACGAATACCTG \\
\hline EDC413_cat-f & CAGGTATTCGTCAGCCGTAAGTCAACTCTTCCTGTCGTC \\
\hline EDC414_cat-1-r & GAGATTATCAAAAAGGATCTTCACC \\
\hline $\begin{array}{l}\text { JGP146_Loc9.8 } \\
b_{-} \text {T1T2DE3cat }\end{array}$ & $\begin{array}{l}\text { G*A*TTGCAGGAAAACTCGGTTAACGGAGTGATCGAGTTAACATTGTGA } \\
\text { TTTTCAGCCTGATACAG }\end{array}$ \\
\hline $\begin{array}{l}\text { JGP147_Loc9.8 } \\
\text { b_T1T2DE3cat } \\
\text { r }\end{array}$ & $\begin{array}{l}{ }^{*} \text { A*CACAGCAACCATGTAAATCGGAGTTGAAACCAATATTTAACTTAGA } \\
\text { GATTATCAAAAAGGATCTTCACC }\end{array}$ \\
\hline $\begin{array}{l}\text { JGP173_Hom8. } \\
\text { 9bseq_f3 }\end{array}$ & GAACTTAATGCAACACACCA \\
\hline $\begin{array}{l}\text { JGP292_T7RN } \\
\text { APr_seq }\end{array}$ & CCGCGCTTAGCTTTCACT \\
\hline $\begin{array}{l}\text { EDC280_T7seq } \\
1\end{array}$ & CCATCAACAGTATTATTTTCTCC \\
\hline $\begin{array}{l}\text { EDC282_T7seq } \\
3\end{array}$ & GGTGAAGCACGCTTCC \\
\hline $\begin{array}{l}\text { JGP153_Hom8. } \\
\text { 9bseq_r }\end{array}$ & CGTGTGCGTGTCCATAGA \\
\hline $\begin{array}{l}\text { JGP389_T7cas } \\
\text { sCmR_ko_MAG } \\
\text { E }\end{array}$ & $\begin{array}{l}\mathrm{G}^{*} T^{*} \mathrm{C}^{*} T^{*} \mathrm{GCAGAAAAAAAGCCCGCTTATTAGGCGGGCTAGGAGTGAGT} \\
\text { GTGTGTTTAAGTTCCACACATTATTCGAGCCGGATGAGTAATTGT }\end{array}$ \\
\hline EDC413_cat-f & CAGGTATTCGTCAGCCGTAAGTCAACTCTTCCTGTCGTC \\
\hline $\begin{array}{l}\text { JGP211_Hom8. } \\
\text { 9bscreen_r1 }\end{array}$ & GCACCATGAAATCCTGCA \\
\hline
\end{tabular}


Supplemental Table 3. T7RNAP cassette parts.

\begin{tabular}{|c|c|}
\hline T7RNAP parts & DNA Sequence \\
\hline TM piece & $\begin{array}{l}\text { CGATTTTCAGCCTGATACAGATTAAATCAGAACGCAGAAGCGGTCTGA } \\
\text { TAAAACAGAATTTGCCTGGCGGCAGTAGCGCGGTGGTCCCACCTGAC } \\
\text { CCCATGCCGAACTCAGAAGTGAAACGCCGTAGCGCCGATGGTAGTGT } \\
\text { GGGGTCTCCCCATGCGAGAGTAGGGAACTGCCAGGCATCAAATAAAA } \\
\text { CGAAAGGCTCAGTCGAAAGACTGGGCCTTTCGTTTTATCTGTTGTTTG } \\
\text { TCGGTGAACGCTCTCCTGAGTAGGACAAATCCGCCGGGAGCGGATTT } \\
\text { GAACGTTGCGAAGCAACGGCCCGGAGGGTGGCGGGCAGGACGCCC } \\
\text { GCCATAAACTGCCAGGCATCAAATTAAGCAGAAGGCCATCCTGACGG } \\
\text { ATGGCCTTTTTGCGTTTCTACA }\end{array}$ \\
\hline T7RNAP piece & $\begin{array}{l}\text { CCTTTTTGCGTTTCTACAGCTTTTTTATACTAAGTTGGCATTATAAAAAA } \\
\text { GCATTGCTTATCAATTGTTGCAACGAACAGGTCACTATCAGTCAAAAT } \\
\text { AAAATCATTATTTGATTTCAATTTTGTCCCACTCCCTGCCTCTGTCATC } \\
\text { ACGATACTGTGATGCCATGGTGTCCGACTTATGCCCGAGAAGATTT } \\
\text { GAGCAAACTTATCGCTTATCTGCTTCTCATAGAGTCTTGCAGACAAAC } \\
\text { TGCGCAACTCGTGAAAGGTAGGCGGATCCAGATCCCGGACACCATCG } \\
\text { AATGGCGCAAAACCTTTCGCGGTATGGCATGATAGCGCCCGGAAGAG } \\
\text { AGTCAATTCAGGGTGGTGAATGGAAACCAGTAACGTTATACGATGTC } \\
\text { GCAGAGTATGCCGGTGTCTCTTATCAGACCGTTTCCCGCGTGGTGAA } \\
\text { CCAGGCCAGCCACGTTTCTGCGAAAACGCGGGAAAAGTGGAAGCG } \\
\text { GCGATGGCGGAGCTGAATTACATTCCCAACCGCGTGGCACAACAACT } \\
\text { GGCGGGCAAACAGTCGTTGCTGATTGGCGTTGCCACCTCCAGTCTGG } \\
\text { CCCTGCACGCGCCGTCGCAAATTGTCGCGGCGATTAAATCTCGCGCC } \\
\text { GATCAACTGGGTGCCAGCGTGGTGGTGTCGATGGTAGAACGAAGCG } \\
\text { GCGTCGAAGCCTGTAAAGCGGCGGTGCACAATCTTCTCGCGCAACGC } \\
\text { GTCAGTGGGCTGATCATTAACTATCCGCTGGATGACCAGGATGCCATT } \\
\text { GCTGTGGAAGCTGCCTGCACTAATGTTCCGGCGTTATTTCTTGATGTC } \\
\text { TCTGACCAGACACCCATCAACAGTATTATTTCTCCCATGAAGACGGT } \\
\text { ACGCGACTGGGCGTGGAGCATCTGGTCGCATTGGGTCACCAGCAAAT } \\
\text { CGCGCTGTTAGCGGGCCCATTAAGTTCTGTCTCGGCGCGTCTGCGTC } \\
\text { TGGCTGGCTGGCATAAATATCTCACTCGCAATCAAATTCAGCCGATAG } \\
\text { CGGAACGGGAAGGCGACTGGAGTGCCATGTCCGGTTTTCAACAAACC } \\
\text { ATGCAAATGCTGAATGAGGGCATCGTTCCCACTGCGATGCTGGTTGC } \\
\text { CAACGATCAGATGGCGCTGGGCGCAATGCGCGCCATTACCGAGTCC } \\
\text { GGGCTGCGCGTTGGTGCGGATATCTCGGTAGTGGGATACGACGATAC } \\
\text { CGAAGACAGCTCATGTTATATCCCGCCGTTAACCACCATCAAACAGGA } \\
\text { TTTTCGCCTGCTGGGGCAAACCAGCGTGGACCGCTTGCTGCAACTCT } \\
\text { CTCAGGGCCAGGCGGTGAAGGGCAATCAGCTGTTGCCCGTCTCACT } \\
\text { GGTGAAAAGAAAACCACCCTGGCGCCCAATACGCAAACCGCCTCTC } \\
\text { CCCGCGCGTTGGCCGATTCATTAATGCAGCTGGCACGACAGGTTTCC } \\
\text { CGACTGGAAAGCGGGCAGTGAGCGCAACGCAATTAATGTAAGTTAGC } \\
\text { TCACTCATTAGGCACCCCAGGCTTTACACTTTATGCTTCCGGCTCGTA } \\
\text { TAATGTGTGGAATTGTGAGCGGATAACAATTTCACACAGGAAACAGCT } \\
\text { ATGACCATGATTACGGATTCACTGGCCGTCGTTTTACAACGTCGTGAC } \\
\text { TGGGAAAACCCTGGCGTTACCCAACTTAATCGCCTTGCAGCACATCC } \\
\text { CCCTTTCGCCAGCTGGCGTAATAGCGAAGAGGCCCGCACCGATCGC } \\
\text { CCTTCCCAACAGTTGCGCAGCCTGAATGGCGAATGGCGCTTTGCCTG } \\
\text { GTTTCCGGCACCAGAAGCGGTGCCGGAAAGCTGGCTGGAGTGCGAT } \\
\text { CTTCCTGAGGCCGATACTGTCGTCGTCCCCTCAAACTGGCAGATGCA } \\
\text { CGGTTACGATGCGCCCATCTACACCAACGTGACCTATCCCATTACGGT }\end{array}$ \\
\hline
\end{tabular}


CAATCCGCCGTTTGTTCCCACGGAGAATCCGACGGGTTGTTACTCGC TCACATTTAATGTTGATGAAAGCTGGCTACAGGAAGGCCAGACGCGA ATTATTTTTTGATGGCGTCGGGATCTGATCCGGATTTACTAACTGGAAG AGGCACTAAATGAACACGATTAACATCGCTAAGAACGACTTCTCTGAC ATCGAACTGGCTGCTATCCCGTTCAACACTCTGGCTGACCATTACGGT GAGCGTTTAGCTCGCGAACAGTTGGCCCTTGAGCATGAGTCTTACGA GATGGGTGAAGCACGCTTCCGCAAGATGTTTGAGCGTCAACTTAAAG CTGGTGAGGTTGCGGATAACGCTGCCGCCAAGCCTCTCATCACTACC CTACTCCCTAAGATGATTGCACGCATCAACGACTGGTTTGAGGAAGTG AAAGCTAAGCGCGGCAAGCGCCCGACAGCCTTCCAGTTCCTGCAAGA AATCAAGCCGGAAGCCGTAGCGTACATCACCATTAAGACCACTCTGG CTTGCCTAACCAGTGCTGACAATACAACCGTTCAGGCTGTAGCAAGC GCAATCGGTCGGGCCATTGAGGACGAGGCTCGCTTCGGTCGTATCC GTGACCTTGAAGCTAAGCACTTCAAGAAAAACGTTGAGGAACAACTCA ACAAGCGCGTAGGGCACGTCTACAAGAAAGCATTTATGCAAGTTGTC GAGGCTGACATGCTCTCTAAGGGTCTACTCGGTGGCGAGGCGTGGTC TTCGTGGCATAAGGAAGACTCTATTCATGTAGGAGTACGCTGCATCGA GATGCTCATTGAGTCAACCGGAATGGTTAGCTTACACCGCCAAAATGC TGGCGTAGTAGGTCAAGACTCTGAGACTATCGAACTCGCACCTGAATA CGCTGAGGCTATCGCAACCCGTGCAGGTGCGCTGGCTGGCATCTCTC CGATGTTCCAACCTTGCGTAGTTCCTCCTAAGCCGTGGACTGGCATTA CTGGTGGTGGCTATTGGGCTAACGGTCGTCGTCCTCTGGCGCTGGTG CGTACTCACAGTAAGAAAGCACTGATGCGCTACGAAGACGTTTACATG CCTGAGGTGTACAAAGCGATTAACATTGCGCAAAACACCGCATGGAA AATCAACAAGAAAGTCCTAGCGGTCGCCAACGTAATCACCAAGTGGA AGCATTGTCCGGTCGAGGACATCCCTGCGATTGAGCGTGAAGAACTC CCGATGAAACCGGAAGACATCGACATGAATCCTGAGGCTCTCACCGC GTGGAAACGTGCTGCCGCTGCTGTGTACCGCAAGGACAAGGCTCGC AAGTCTCGCCGTATCAGCCTTGAGTTCATGCTTGAGCAAGCCAATAAG TTTGCTAACCATAAGGCCATCTGGTTCCCTTACAACATGGACTGGCGC GGTCGTGTTTACGCTGTGTCAATGTTCAACCCGCAAGGTAACGATATG ACCAAAGGACTGCTTACGCTGGCGAAAGGTAAACCAATCGGTAAGGA AGGTTACTACTGGCTGAAAATCCACGGTGCAAACTGTGCGGGTGTCG ATAAGGTTCCGTTCCCTGAGCGCATCAAGTTCATTGAGGAAAACCACG AGAACATCATGGCTTGCGCTAAGTCTCCACTGGAGAACACTTGGTGG GCTGAGCAAGATTCTCCGTTCTGCTTCCTTGCGTTCTGCTTTTGAGTAC GCTGGGGTACAGCACCACGGCCTGAGCTATAACTGCTCCCTTCCGCT GGCGTTTGACGGGTCTTGCTCTGGCATCCAGCACTTCTCCGCGATGC TCCGAGATGAGGTAGGTGGTCGCGCGGTTAACTTGCTTCCTAGTGAA ACCGTTCAGGACATCTACGGGATTGTTGCTAAGAAAGTCAACGAGATT CTACAAGCAGACGCAATCAATGGGACCGATAACGAAGTAGTTACCGT GACCGATGAGAACACTGGTGAAATCTCTGAGAAAGTCAAGCTGGGCA CTAAGGCACTGGCTGGTCAATGGCTGGCTTACGGTGTTACTCGCAGT GTGACTAAGCGTTCAGTCATGACGCTGGCTTACGGGTCCAAAGAGTT CGGCTTCCGTCAACAAGTGCTGGAAGATACCATTCAGCCAGCTATTTGA TTCCGGCAAGGGTCTGATGTTCACTCAGCCGAATCAGGCTGCTGGAT ACATGGCTAAGCTGATTTGGGAATCTGTGAGCGTGACGGTGGTAGCT GCGGTTGAAGCAATGAACTGGCTTAAGTCTGCTGCTAAGCTGCTGGC TGCTGAGGTCAAAGATAAGAAGACTGGAGAGATTCTTCGCAAGCGTT GCGCTGTGCATTGGGTAACTCCTGATGGTTTCCCTGTGTGGCAGGAA TACAAGAAGCCTATTCAGACGCGCTTGAACCTGATGTTCCTCGGTCAG 


\begin{tabular}{|c|c|}
\hline & $\begin{array}{l}\text { TTCCGCTTACAGCCTACCATTAACACCAACAAAGATAGCGAGATTGAT } \\
\text { GCACACAAACAGGAGTCTGGTATCGCTCCTAACTTTGTACACAGCCAA } \\
\text { GACGGTAGCCACCTTCGTAAGACTGTAGTGTGGGCACACGAGAAGTA } \\
\text { CGGAATCGAATCTTTTGCACTGATTCACGACTCCTTCGGTACCATTCC } \\
\text { GGCTGACGCTGCGAACCTGTTCAAAGCAGTGCGCGAAACTATGGTTG } \\
\text { ACACATATGAGTCTTGTGATGTACTGGCTGATTTCTACGACCAGTTCG } \\
\text { CTGACCAGTTGCACGAGTCTCAATTGGACAAAATGCCAGCACTTCCG } \\
\text { GCTAAAGGTAACTTGAACCTCCGTGACATCTTAGAGTCGGACTTCGCG } \\
\text { TTCGCGTAACGCCAAATCAATACGACTCCGGATCCCCTTCGAAGGAAA } \\
\text { GACCTGATGCTTTTGTGCGCGCATAAAATACCTTGATACTGTGCCGG } \\
\text { ATGAAAGCGGTTCGCGACGAGTAGATGCAATTATGGTTTCTCCGCCAA } \\
\text { GAATCTCTTTGCATTTATCAAGTGTTTCTTCATTGATATTCCGAGAGC } \\
\text { ATCAATATGCAATGCTGTTGGGATGGCAATTTTTACGCCTGTTTTGCTT } \\
\text { TGCTCGACATAAAGATATCCATCTACGATATCAGACCACTTCATTTCGC } \\
\text { ATAAATCACCAACTCGTTGCCCGGTAACAACAGCCAGTTCCATTGCAA } \\
\text { GTCTGAGCCAACATGGTGATGATTCTGCTGCTTGATAAATTTTCAGGT } \\
\text { ATTCGTCAGCCGTAAGTC }\end{array}$ \\
\hline CmR Piece & $\begin{array}{l}\text { CAGGTATTCGTCAGCCGTAAGTCAACTCTTCCTGTCGTCATATCTACA } \\
\text { AGCCGGCGCGCCAAATTGACAATTACTCATCCGGCTCGAATAATGTGT } \\
\text { GGAACTTAAACACACACAGGAGGAAAACATATGGAAAAAAAAATCACC } \\
\text { GGCTACACCACCGTTGACATCTCTCAGTGGCACCGTAAAGAACACTTT } \\
\text { GAAGCGTTCCAGTCTGTCGCGCAGTGTACCTACAACCAGACCGTTCA } \\
\text { GCTAGACATCACCGCGTTCCTGAAAACCGTTAAAAAAACAAACACAA } \\
\text { ATTCTACCCGGCGTTCATTCACATCCTGGCGCGTCTGATGAACGCGC } \\
\text { ACCCGGAATTTCGTATGGCGATGAAAGACGGTGAACTGGTTATCTGG } \\
\text { GACTCTGTTCACCCGTGCTACACCGTTTTCCACGAACAGACCGAAACC } \\
\text { TTCTCTTCTCTGTGGTCTGAATACCACGACGACTTCCGTCAGTTCCTG } \\
\text { CACATCTACTCTCAGGACGTTGCGTGCTACGGTGAAAACCTGGCGTA } \\
\text { CTTCCCGAAAGGTTTCATCGAAAACATGTTCTTCGTTTCTGCGAACCC } \\
\text { GTGGGTTTCTTTCACCTCTTTCGACCTGAACGTGGCGAACATGGACAA } \\
\text { CTTCTTCGCGCCGGTTTTCACTATGGGTAAATACTACACCCAGGGTGA } \\
\text { CAAAGTTCTGATGCCGCTGGCGATCCAGGTTCACCACGCGGTTTGCG } \\
\text { ACGGTTTCCACGTTGGTCGTATGCTGAACGAACTCCAGCAGTATTGC } \\
\text { GACGAATGGCAGGGTGGTGCGTAAACTCACTCCTAGCCCGCCTAATA } \\
\text { AGCGGGCTTTTTTTCTGCAGACCAAGTTTACTCATATATACTTTAGATT } \\
\text { GATTTAAAACTTCATTTTTAATTAAAAGGATCTAGGTGAAGATCCTTTT } \\
\text { TGATAATCTC }\end{array}$ \\
\hline
\end{tabular}




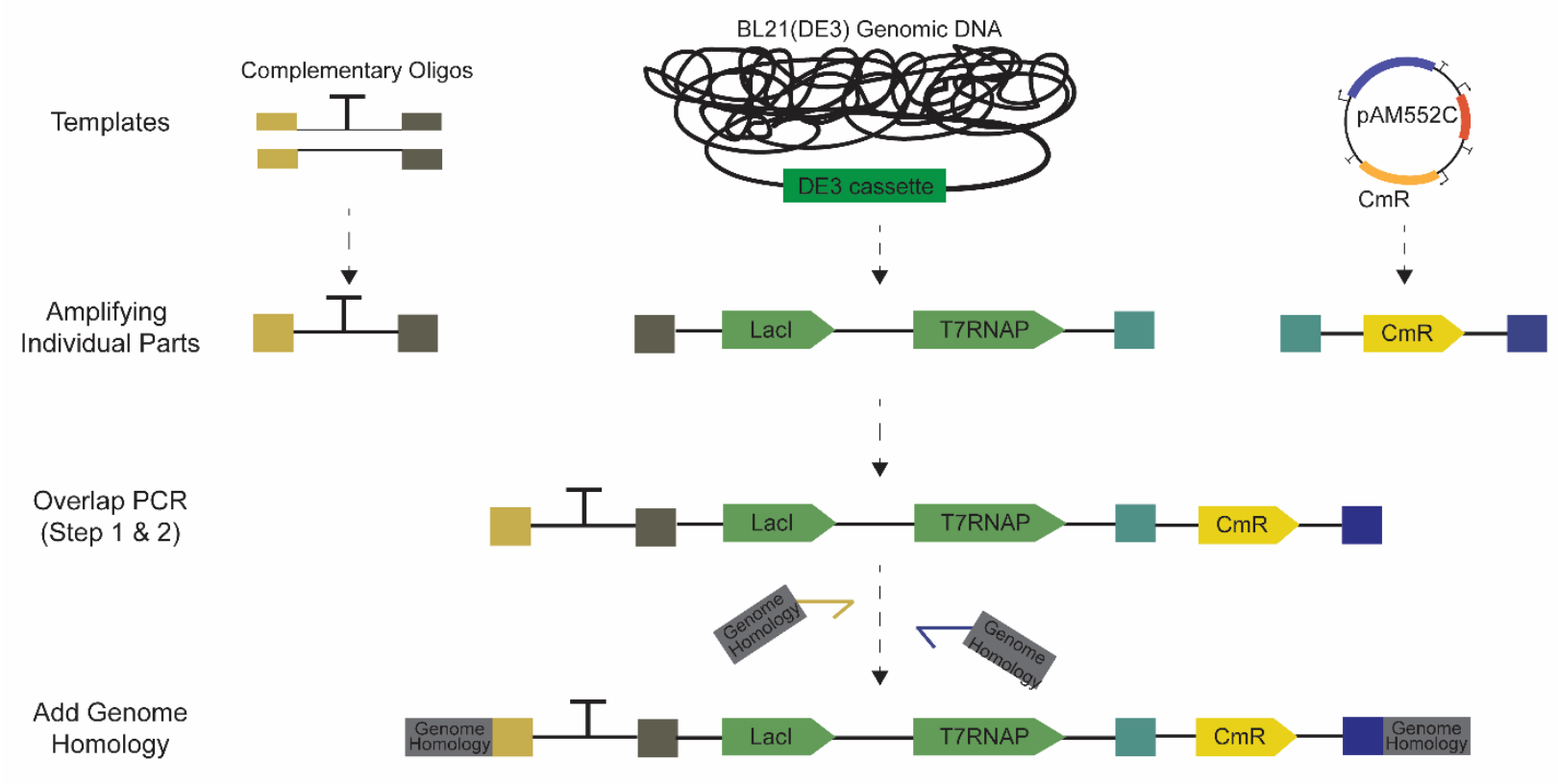

Supplemental Figure 1. Construction of the T7RNAP cassette. The T7RNAP cassette consists of three parts: 5' Terminator (TM), T7 RNA Polymerase (T7RNAP) and antibiotic resistance marker $\mathrm{CmR}$. These parts were amplified from various sources and were stitched together via overlap PCR using a two-step amplification process. During the stitching process homology to the genomic insertion site was added to the 5' and 3' end of the cassette. 
A

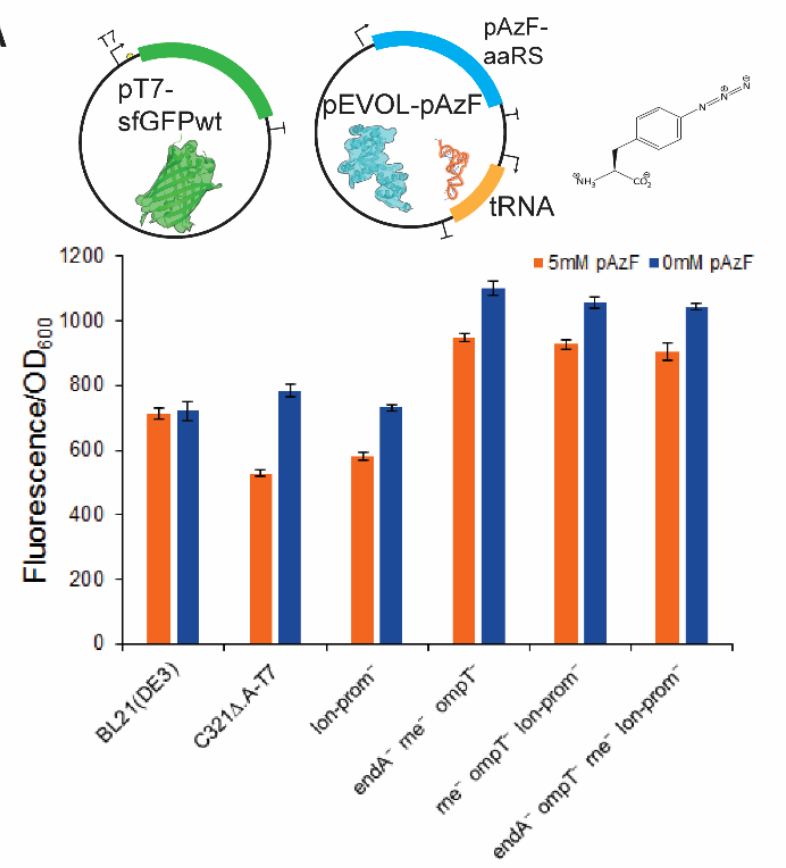

B
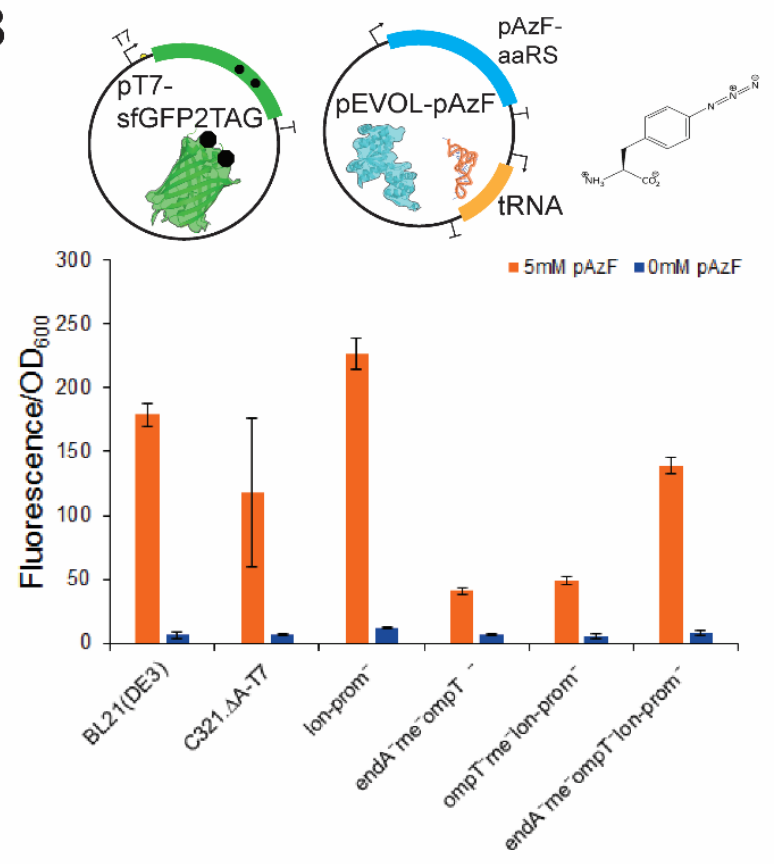

Supplemental Figure 2. Expression of sfGFP in top C321. $A A$ mutants containing genomically expressed T7RNAP cassette. A) T7RNAP function was tested in the top C321. $\triangle A$ mutants by expressing wild-type sfGFP (sfGFP-wt) with the pAzF orthogonal translation system expressed on pEVOL-pAzF. For all conditions $1 \mathrm{mM} \mathrm{IPTG}, 0.02 \%$ arabinose and $5 \mathrm{mM} \mathrm{pAzF}$ (orange bars) or $0 \mathrm{mM}$ pAzF (blue bars) was added at $\mathrm{OD}_{600}$ 0.6-0.8. B) Modified C321. $\triangle A-T 7$ strains were analyzed for the ability to suppress two amber codons at positions 190 and 212 in the presence (orange) or absence (blue) of $5 \mathrm{mM} \mathrm{pAzF}$. For all panels error bars represent one standard deviation for biological triplicates and technical triplicates. 

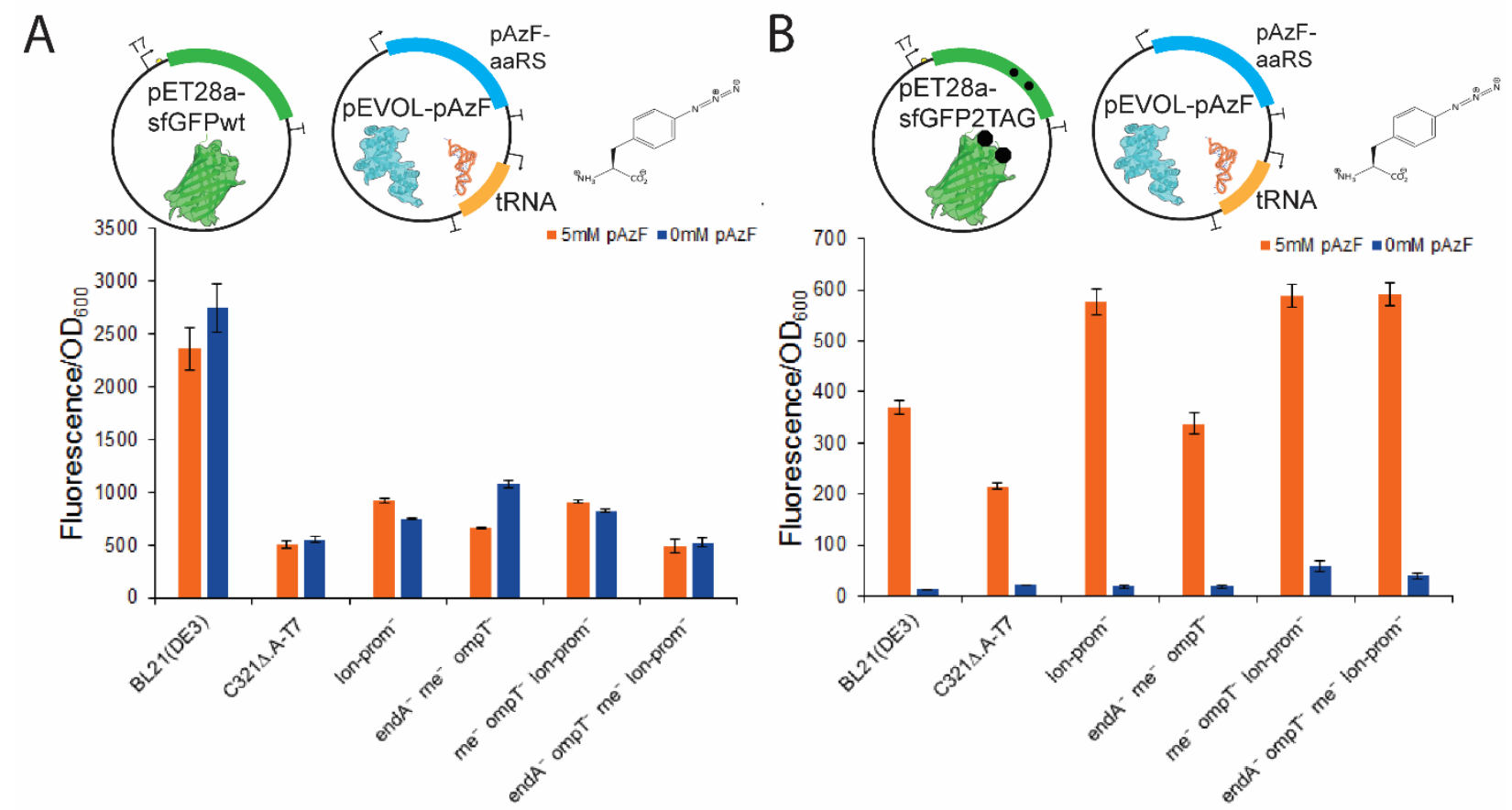

Supplemental Figure 3. Expression of sfGFP in C321. $A$ A-T7 strains using a pET reporter plasmid. A) SfGFP-wt and the pAzF orthogonal translation system was expressed using a pET

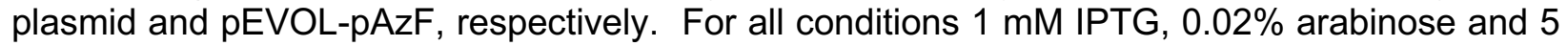
$\mathrm{mM}$ pAzF (orange bars) or $0 \mathrm{mM} \mathrm{pAzF}$ (blue bars) were added at $\mathrm{OD}_{600}$ 0.6-0.8. B) Expression of sfGFP with two amber codons at positions 190 and 212 in the presence (orange) or absence (blue) of $5 \mathrm{mM}$ pAzF was tested with pEVOL-pAzF. For all panels error bars represent one standard deviation for biological triplicates and technical triplicates. 
A

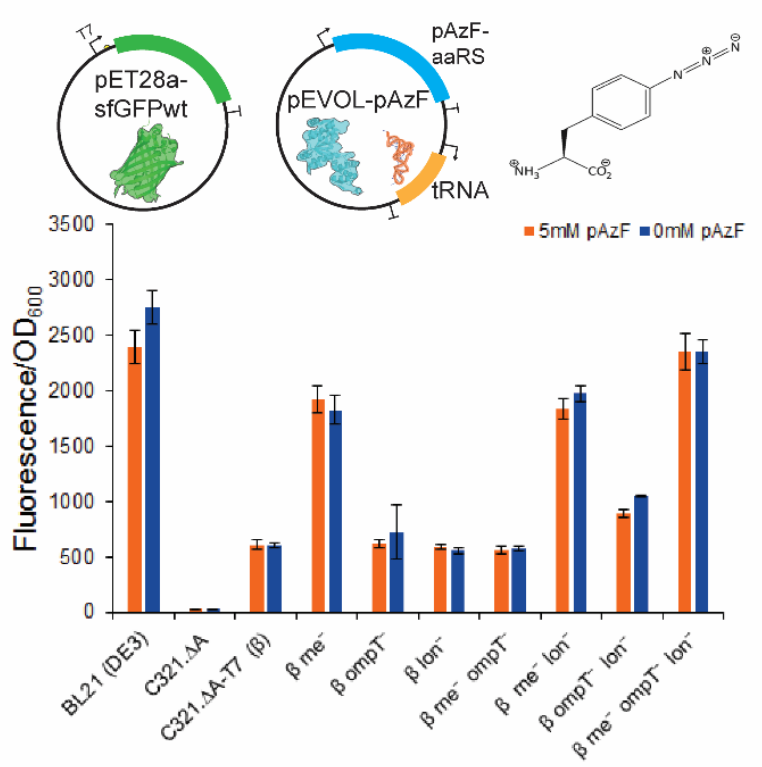

$B$

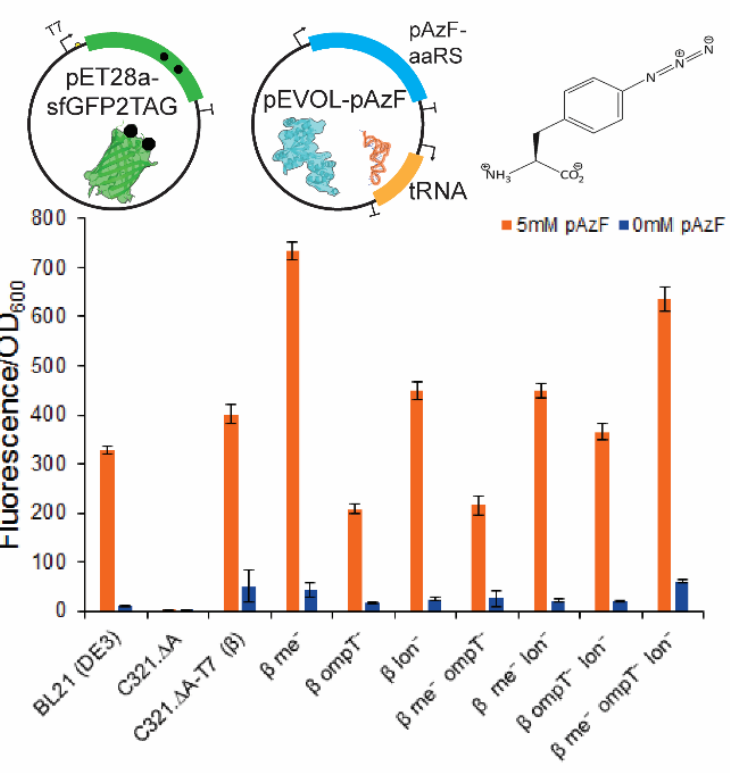

Supplemental Figure 4. Expression of sfGFP in C321. $\triangle A-T 7$ strains produced by first inserting T7RNAP, followed by the introduction of protein and nuclease mutations. A) Expression of sfGFP-wt was performed using pET28a-sfGFP-wt and pEVOLpAzF. For all conditions $1 \mathrm{mM}$ IPTG, $0.02 \%$ arabinose and $5 \mathrm{mM} \mathrm{pAzF}$ (orange bars) or $0 \mathrm{mM} \mathrm{pAzF}$ (blue bars) were added at $\mathrm{OD}_{600}$ 0.6-0.8. B) Expression of sfGFP with two amber codons at positions 190 and 212 in the presence (orange) or absence (blue) of $5 \mathrm{mM} \mathrm{pAzF}$ was tested with pEVOL-pAzF. For all panels error bars represent one standard deviation for biological triplicates and technical triplicates. 


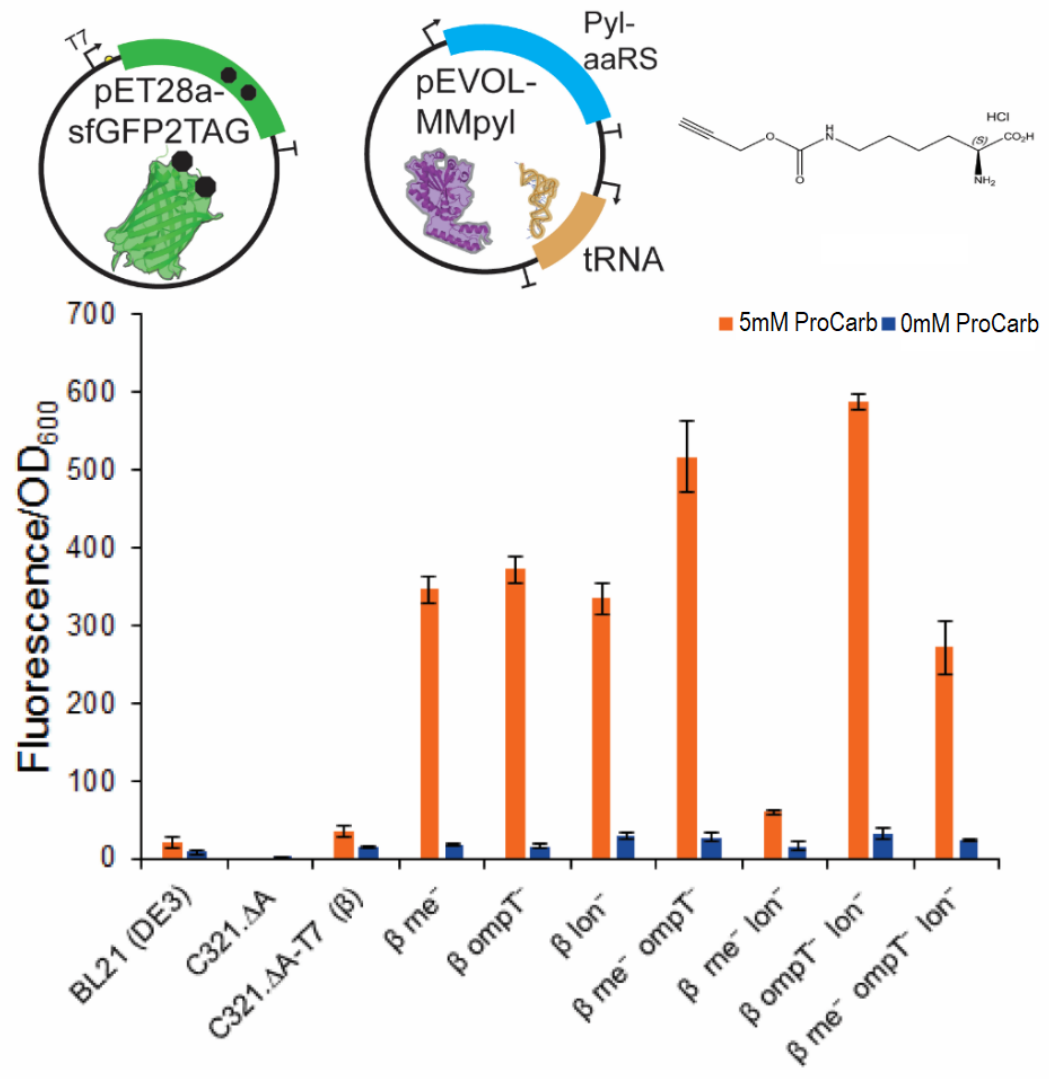

Supplemental Figure 5. Expression of sfGFP-2TAG utilizing the pyrrolysine orthogonal translation system in $\boldsymbol{\beta}$ strains. Expression of sfGFP with two amber codons at positions 190 and 212 in the presence (orange) or absence (blue) of $5 \mathrm{mM}$ ProCarb was tested with pEVOLMMpyl. Error bars represent one standard deviation for biological triplicates and technical triplicates. 